THE DEMAND FOR BEER, WINE AND SPIRITS:

\title{
A SYSTEM-WIDE ANALYSIS,
}

Kenneth W. Clements The University of Western Australia

and

Lester W. Johnson

Macquarie University

Discussion Paper 82.12

June 1982 
THE DEMAND FOR BEER, WINE AND SPIRITS:

A SYSTEM-WIDE ANALYSIS*

by

Kenneth $W$. Clements

Department of Economics

The University of Western Australia

(09) 380.2928

and

Lester W. Johnson

School of Economic and Financial Studies

Macquarie University

(02) 88.9604

* We are indebted to John Davis, Peter Goldschmidt and Kal stening for excellent research assistance; and to the New South Wales Drug and Alcohol Authority for their partial financial support of this research. 


\section{INTRODUCTION}

The system-wide approach to the analysis of consumer demand considers the multivariate structure of the problem in which the consumer allocates his income to all goods simultaneously. This approach combines the theory of the consumer with empirical analysis and has enjoyed much popularity over the past decade. For surveys of these developments, see Barten (1977), Brown and Deaton (1972), Phlips (1974), Powell (1974), Theil (1975/76, 1980) and Theil and Clements (1980).

Most previous applications of the system-wide approach have used national accounts commodity groups (food, clothing, housing and so on). For many business and government policy purposes, however, these groups are much too broad. For example, to analyse the effects on consumption of all but the simplest changes in indirect taxes, we would need considerably more disaggregation. Similarly, market researchers need to analyse demand at the individual product level for purposes of forecasting and formulating pricing and other policies. The objective of this paper is to use the consumption of beer, wine and spirits to illustrate how the approach can be applied to give insights into the structure of demand for more narrowly defined commodity groups. When the consumer's utility function is appropriately separable in alcoholic beverages and all other goods, it is possible to confine our attention to the three beverages and ignore all other goods. In Section 2 of the paper we set out the so-called differential version of the system-wide approach. In section 3 we use the alcohol data to estimate demand equations for beer, wine and spirits. We then use the demand model in sections 4 and 5 to (i) explain the rapid growth of wine consumption and (ii) measure the welfare cost of alcohol taxes. Section 6 contains concluding comments. In a subsequent paper we will use the demand equations to formulate optimal tax packages for the alcoholic beverages. 


\section{DIFFERENTIAL DEMAND EQUATIONS}

In this section we first formulate the consumer's demand equations for all $\mathrm{n}$ goods in terms of differentials. These are unconditional demand equations as they depend on all prices and total expenditure. The coefficients of these equations are not necessarily taken to be constant, so the model is general. We then block the $\mathrm{n}$ goods such that they form groups which are separable in the consumer's utility function. This leads to a composite demand equation for each group, as well as conditional demand equations within each group. The variables of the conditional equation are exclusively concerned with the group to which the good belongs, allowing us to focus attention on demand within the group. Finally, for estimation we set out a Rotterdam parametrization. This section is based on Theil (1975/76, 1980).

Unconditional Demand Equations

We write $p_{i}, q_{i}$ for the price and quantity demanded for good $i$ $(i=1, \ldots, n), M=\sum_{i=1}^{n} p_{i} q_{i}$ for total expenditure ("income" for short), and $w_{i}=p_{i} q_{i} / M$ for the $i$ th budget share. Under general conditions, the demand for good $i$ can be written as (see Appendix)

$$
w_{i} d\left(\log q_{i}\right)=\theta_{i} d(\log Q)+\sum_{j=1}^{n} v_{i j} d\left(\log \frac{p_{j}}{p^{j}}\right),
$$

where $\theta_{i}=\partial\left(p_{i} q_{i}\right) / \partial M$ is the $i^{\text {th }}$ marginal share; $d(\log Q)=\sum_{i=1}^{n} w_{i} d\left(\log q_{i}\right)$ is the Divisia volume index of the change in the consumer's real income; $d\left(\log p_{j} / P^{\prime}\right)$ is to be interpreted as the change in the deflated price of $j$ $d\left(\log p_{j}\right)-d\left(\log P^{\prime}\right)$, where $d\left(\log P^{\prime}\right)=\sum_{i=1}^{n} \theta_{i} d\left(\log p_{i}\right)$ is the Frisch price index; and

$$
v_{i j}=\lambda p_{i}{ }^{i j} p_{j} / M
$$

is the $(i, j)$ th price coefficient, where $\lambda$ is the marginal utility of income 
and $u^{i j}$ is the $(i, j)^{\text {th }}$ element of the inverse of the Hessian of the utility function $\left[\partial^{2} u / \partial q_{i} \partial q_{j}\right]^{-1}$. In view of (2), the symmetry of this Hessian means that the matrix of price coefficients $\left[\nu_{i j}\right]$ is also symmetric. A sufficient second-order condition for a budget-constrained maximum is that the Hessian be negative definite; (2) thus implies that $\left[\nu_{i j}\right]$ is negative definite.

The variable on the left of (I) has the dual interpretation as (i) the contribution of good $i$ to the Divisia volume index and (ii) the quantity component of the change in $w_{i}, d w_{i}=w_{i} d\left(\log p_{i}\right)+w_{i} d\left(\log q_{i}\right)-w_{i} d(\log M)$. Equation (1) explains the change in the demand for $i$ in terms of changes in real income and relative prices. By dividing both sides by $w_{i}$, we find that $\theta_{i} / w_{i}$ and $\nu_{i j} / w_{i}$ are the income and price elasticities, respectively. The marginal share $\theta_{i}$ tells us what fraction of an additional dollar of income is spent on good $i$, with $\Sigma_{i} \theta_{i}=1$. The price coefficient matrix $\left[\nu_{i j}\right]$ is interpreted as being inversely proportional to the Hessian matrix of the utility function in expenditure terms (Theil, 1975/76, p. 29). The price coefficients are subject to the constraint that the row sums of $\left[\nu_{i j}\right]$ are proportional to the corresponding marginal shares (see Appendix),

$$
\sum_{j=1}^{n} v_{i j}=\phi \theta_{i}
$$$$
i=1, \ldots, n \text {, }
$$

where $\phi=(\partial \log \lambda / \partial \log M)^{-1}$ is the reciprocal of the income elasticity of the marginal utility of income. We shall refer to $\phi$ as the income flexibility.

\section{Block-Independent Preferences}

Let the $n$ goods now be divided into $G$ groups, $s_{1} \ldots, s_{G}$, such that each good belongs to only one group. Further, let the consumer's preferences be such that the utility function is the sum of $G$ sub-utility functions, each involving the quantities of only one group,

$$
u(q)=\sum_{g=1}^{G} u_{g}\left(q_{g}\right),
$$


where $q=\left[q_{1}, \ldots, q_{n}\right]^{\prime}$ and $q_{g}$ is the vector of the $q_{i}$ 's that fall under $s_{g}$. Then, when the goods are numbered appropriately, the Hessian $\left[\partial^{2} u / \partial q_{i} \partial q_{j}\right]$ and its inverse become block-diagonal. Accordingly, specification (4) is known as block-independent preferences (Theil, 1975/76).

Under block-independence, $\nu_{i j}=0$ for $i$ and $j$ in different groups [see (2)] and (3) for $i \in S_{g}$ becomes

$$
\sum_{j \in S_{g}} \nu_{i j}=\phi \theta_{i} \quad g=1, \ldots, G:
$$

The demand equation ( 1 ) for $i \in S_{g}$ becomes

$$
w_{i} d\left(\log q_{i}\right)=\theta_{i} d(\log Q)+\sum_{j \in S_{g}} v_{i j} d\left(\log \frac{p_{j}}{P^{\prime}}\right)
$$

so that the only deflated prices which appear are those of goods belonging to the same group as i.

\section{Composite Demand Equations}

We write $\mathrm{w}_{\mathrm{g}}=\Sigma_{i \in S_{\mathrm{g}}} \mathrm{w}_{i}$ and $\theta_{\mathrm{g}}=\Sigma_{i \in S_{g}} \theta_{i}$ for the average and marginal shares of group $g$, and define the group volume and Frisch price indexes as $d\left(\log Q_{g}\right)=\sum_{i \in S_{g}}\left(w_{i} / W_{g}\right) d\left(\log q_{i}\right), d\left(\log P_{g}^{\prime}\right)=\sum_{i \in S_{g}}\left(\theta_{i} / \theta_{g}\right) d\left(\log p_{i}\right)$. If we then add (6) over $i \in S_{g}$ and use (5) and the symmetry of $\left[\nu_{i j}\right]$, we obtain the composite demand equation for $\mathrm{S}_{\mathrm{g}}$ as a group (see Appendix),

$$
w_{g} d\left(\log Q_{g}\right)=\theta_{g} d(\log Q)+\phi \theta_{g} d\left(\log \frac{P_{g}^{\prime}}{P^{\prime}}\right)
$$

Thus only the deflated price of the group $d\left(\log \frac{P^{\prime}}{P^{\prime}}\right)=d\left(\log P_{g}^{\prime}\right)-d\left(\log P^{\prime}\right)$ and income affects the demand for the group as a whole. The income and own-price elasticities for the group are $\theta_{g} / W_{g}$ and $\phi \theta_{g} / W_{g}$, respectively. This own-price elasticity is the elasticity of the Divisia volume index of the group with respect to the Frisch-deflated Frisch price index of the group. 
Conditional Demand Equations

Combining (6) and (7) we obtain (see Appendix)

$$
w_{i} d\left(\log q_{i}\right)=\frac{\theta_{i}}{\theta_{g}} w_{g} d\left(\log Q_{g}\right)+\sum_{j \in S_{g}} v_{i j} d\left(\log \frac{p_{j}}{P_{g}^{i}}\right) \text {. }
$$

This is the demand equation for $i \in S_{g}$, given the demand for the group as a whole $w_{g} d\left(\log Q_{g}\right)$. As the variables on the right of this equation are exclusively concerned with the group $s_{g}$ to which the $i^{\text {th }}$ commodity belongs, it is known as a conditional demand equation. The term $\theta_{i} / \theta_{g}$ is the conditional marginal share of $i$ within the group $s_{g}$, with $\Sigma_{i \in S_{g}} \theta_{i} / \theta_{g}=1$. This share answers the question, if income increases by one dollar, resulting in a certain additional amount spent on the group $S_{g}$, what is the proportion of this additional amount that is allocated to $i$ ?

Equation (8) can be formulated in terms of absolute (undeflated) prices by using the definition of $d\left(\log P_{g}^{\prime}\right)[$ see above $(7)]$ to write the price term as

(9)

$$
\left\{\begin{array}{l}
\sum_{j \in S_{g}} v_{i j}\left[d\left(\log p_{j}\right)-\sum_{k \in S_{g}} \frac{\theta_{k}}{\theta_{g}} d\left(\log p_{k}\right)\right] \\
=\sum_{j \in S_{g}} \nu_{i j} d\left(\log p_{j}\right)-\phi \theta_{i} \sum_{k \in S} \frac{\theta_{k}}{\theta_{g}} d\left(\log p_{k}\right) \\
=\sum_{j \in S_{g}}\left(\nu_{i j}-\phi \theta_{g} \theta_{i} \theta_{j}\right) d\left(\log p_{j}\right)=\sum_{j \in S_{g}} \pi_{i j}^{g} d\left(\log p_{j}\right),
\end{array}\right.
$$

where the first step is based on (5): $\theta_{i}=\theta_{i} / \theta_{g}$ is the conditional marginal share of $i$; and

$$
\pi_{i j}^{g}=\nu_{i j}-\phi \theta_{g} \theta_{i}^{\prime} \theta_{j} \quad i, j \in S_{g}
$$

is the $(i, j)$ th conditional slutsky coefficient. This coefficient describes the effect of a price change of $j$ on the demand for $i\left(i, j \in S_{g}\right)$ under the condition that the total consumption of the group remains constant. 
Substitution of the fourth member of (9) in (8) gives the absolute price version of the conditional demand equation for $i \in S_{g}$,

$$
w_{i} d\left(\log q_{i}\right)=\theta_{i} w_{g} d\left(\log Q_{g}\right)+\sum_{j \in S} \pi_{i j}^{g} d\left(\log p_{j}\right) .
$$

By dividing both sides of this equation by $w_{i}$, we find that $\frac{\theta_{i}}{\theta_{g}} \frac{w_{g}}{w_{i}}=\frac{\theta_{i} / w_{i}}{\theta_{g} / w_{g}}$ is the ratio of the income elasticity of the good to that of the group to which it belongs. We shall refer to this ratio as conditional income elasticity of $i$. We also find that $\pi_{i j}^{g} / w_{i}$ is the conditional price elasticity; i.e. the elasticity of $q_{i}$ with respect to the absolute price $p_{j}$ $\left(i, j \in S_{g}\right)$.

It follows from (5) and (10) and the fact that $\sum_{j \in S_{g}} \theta_{j}^{\prime}=1$ that

$$
\sum_{j \in S_{g}} \pi_{i j}^{g}=0 \quad i \in S_{g} .
$$

This reflects the homogeneity proposition that a proportionate change in all prices in the group, total consumption of the group remaining unchanged, does not affect the demand for any good in the group. We shall refer to (12) as demand homogeneity.

If $s_{g}$ consists of $n_{g}$ commodities, the $n_{g} \times n_{g}$ matrix of price coefficients referring to $\mathrm{s}_{\mathrm{g}}$ is a principal submatrix of the $\mathrm{n} \times \mathrm{n}$ price coefficient matrix $\left[\nu_{i j}\right]$. As the latter matrix is symmetric, so is the . former. It then follows from (10) that the conditional slutsky matrix [ $\left.\pi_{i j}^{g}\right]$ is symmetric;

$$
\pi_{i j}^{g}=\pi_{j i}^{g}
$$$$
i, j=1, \ldots, n_{g} .
$$

we shall refer to this as slutsky symmetry. The negative definiteness of $\left[v_{i j}\right]$, together with (10) and (12) imply that $\left[\pi_{i j}^{g}\right]$ is negative semidefinite with rank $\mathrm{n}_{\mathrm{g}}-1$. 
A Parametrization of the Conditional Demand Equations

To apply (II) to finite-change data, we replace (i) $w_{i}$ with its arithmetic average over the periods $t-1$ and $t, \bar{w}_{i t}=\left(w_{i t}+w_{i, t-1}\right) / 2$ and (ii) $d(\log x)$ with $D x_{t}=\log x_{t}-\log x_{t-1}$, the $\log$-change in $x$. We also use the Rotterdam parametrization of treating the coefficients of (11) as constants (Theil, 1975/76), so that the estimating equations are

$$
\bar{w}_{i t} D_{i t}=\theta_{i}^{!} \bar{w}_{g t}^{D Q_{g t}}+\sum_{j=1}^{n_{g}} \pi_{i j}^{g} D_{j t}+\varepsilon_{i t}, \quad i=1, \ldots, n_{g}
$$

where $\overrightarrow{\mathrm{w}}_{\mathrm{gt}}=\sum_{i=1}^{\mathrm{n}_{\mathrm{g}}} \overline{\mathrm{w}}_{i t} ; \mathrm{D} \mathrm{Q}_{\mathrm{gt}}=\sum_{i=1}^{\mathrm{n}_{\mathrm{g}}}\left(\overline{\mathrm{w}}_{i t} / \overline{\mathrm{w}}_{\mathrm{gt}}\right) \mathrm{Dq_{it }} ;$ and the $\varepsilon_{i t}$ 's are serially independent, normally distributed disturbances with zero means and a constant contemporaneous covariance matrix.

\section{DEMAND EQUATIONS FOR ALCOHOLIC BEVERAGES}

In this section we first present price-quantity data for the consumption of beer, wine and spirits. We then use these data to estimate (14) under two conditions, (i) that total consumption of alcohol is a predetermined variable and (ii) that it is endogenously determined. Finally, we give the unconditional demand responses.

\section{The Data}

our data refer to the consumption of beer, wine and spirits in Australia over the period 1955/56-1976/77. Table 1 gives the price-quantity data and Table 2 the budget shares. As can be seen, on average beer consumption per capita increased by about 1.2 percent per annum, wine by 4.5 percent and spirits by 2.2 percent. The budget share for total alcohol has remained more or less constant over this period at about 6 percent (Table 2). 
TABLE 1

ALCOHOL QUANTITY AND PRICE LOG-CHANGES:

AUSTRALIA, 1955/56-1976/77

\begin{tabular}{|c|c|c|c|c|c|c|}
\hline \multirow[b]{3}{*}{ Year } & \multicolumn{2}{|c|}{ Beer } & \multicolumn{2}{|c|}{ Wine } & \multicolumn{2}{|c|}{ Spirits } \\
\hline & Quantity & Price & & Price & Quantity & \\
\hline & $\mathrm{Dq} \dot{I}_{I}$ & $\mathrm{Dp}_{1}$ & $\mathrm{Dq}_{2}$ & $\mathrm{Dp}_{2}$ & $\mathrm{Dq}_{3}$ & $\mathrm{Dp}_{3}$ \\
\hline $1956 \% 57$ & -5.359 & 14.205 & -2.447 & 5.982 & -10.427 & 0 \\
\hline $1957 / 58$ & .209 & 1.230 & -.730 & 4.879 & 1.220 & 0 \\
\hline $1958 / 59$ & .476 & .366 & .684 & 6.108 & 4.853 & 0 \\
\hline $1959 / 60$ & 1.735 & .849 & .901 & 7.514 & 8.429 & 0 \\
\hline $1960 / 61$ & -.292 & 1.795 & -2.960 & 7.363 & -.390 & 8.406 \\
\hline $1961 / 62$ & -.410 & .709 & .479 & 1.361 & .289 & 1.315 \\
\hline $1962 / 63$ & 1.235 & .587 & 3.039 & 1.584 & -2.588 & 5.656 \\
\hline $1963 / 64$ & 3.355 & 1.971 & 4.608 & 1.082 & 7.639 & .894 \\
\hline $1964 / 65$ & 3.083 & 1.368 & .708 & 5.809 & 7.271 & 1.982 \\
\hline $1965 / 66$ & .045 & 8.152 & 8.737 & 7.395 & -11.977 & 13.734 \\
\hline $1966 / 67$ & 2.452 & .4 .291 & 11.501 & 4.709 & -.712 & -5.069 \\
\hline $1967 / 68$ & 3.304 & 4.114 & 10.430 & 6.953 & 11.586 & 0 \\
\hline $1968 / 69$ & 3.032 & 3.025 & 8.657 & 12.275 & -1.068 & 6.766 \\
\hline $1969 / 70$ & 2.612 & 3.477 & 8.094 & 6.004 & 10.476 & 2.856 \\
\hline $1970 / 71$ & 1.699 & 6.274 & -3.016 & 9.198 & .939 & 3.041 \\
\hline $1971 / 72$ & -.135 & 5.104 & 1.904 & 5.850 & 5.653 & .264 \\
\hline $1972 / 73$ & 3.010 & 5.238 & 10.084 & -.873 & 12.249 & .875 \\
\hline $1973 / 74$ & 7.028 & 7.623 & 11.430 & 2.924 & .643 & 20.202 \\
\hline $1974 / 75$ & 1.060 & 13.327 & 11.200 & 14.993 & -4.268 & 25.660 \\
\hline $1975 / 76$ & -2.130 & 22.672 & 6.158 & 18.523 & -3.534 & 12.946 \\
\hline $1976 / 77$ & -.965 & 8.943 & 4.463 & 7.748 & 9.773 & .386 \\
\hline Mean & 1.193 & 5.491 & 4.473 & 6.542 & 2.193 & 4.758 \\
\hline
\end{tabular}

The quantities are expressed in per capita terms. The year 1956/57, for example, refers to the transition from 1955/56 to 1956/57. All entries are to be divided by 100 . 
TABLE 2

ARITHMETIC AVERAGES OF UNCONDITIONAL AND CONDITIONAL BUDGET SHARES

FOR ALCOHOL: AUSTRALIA, 1955/56-1976/77

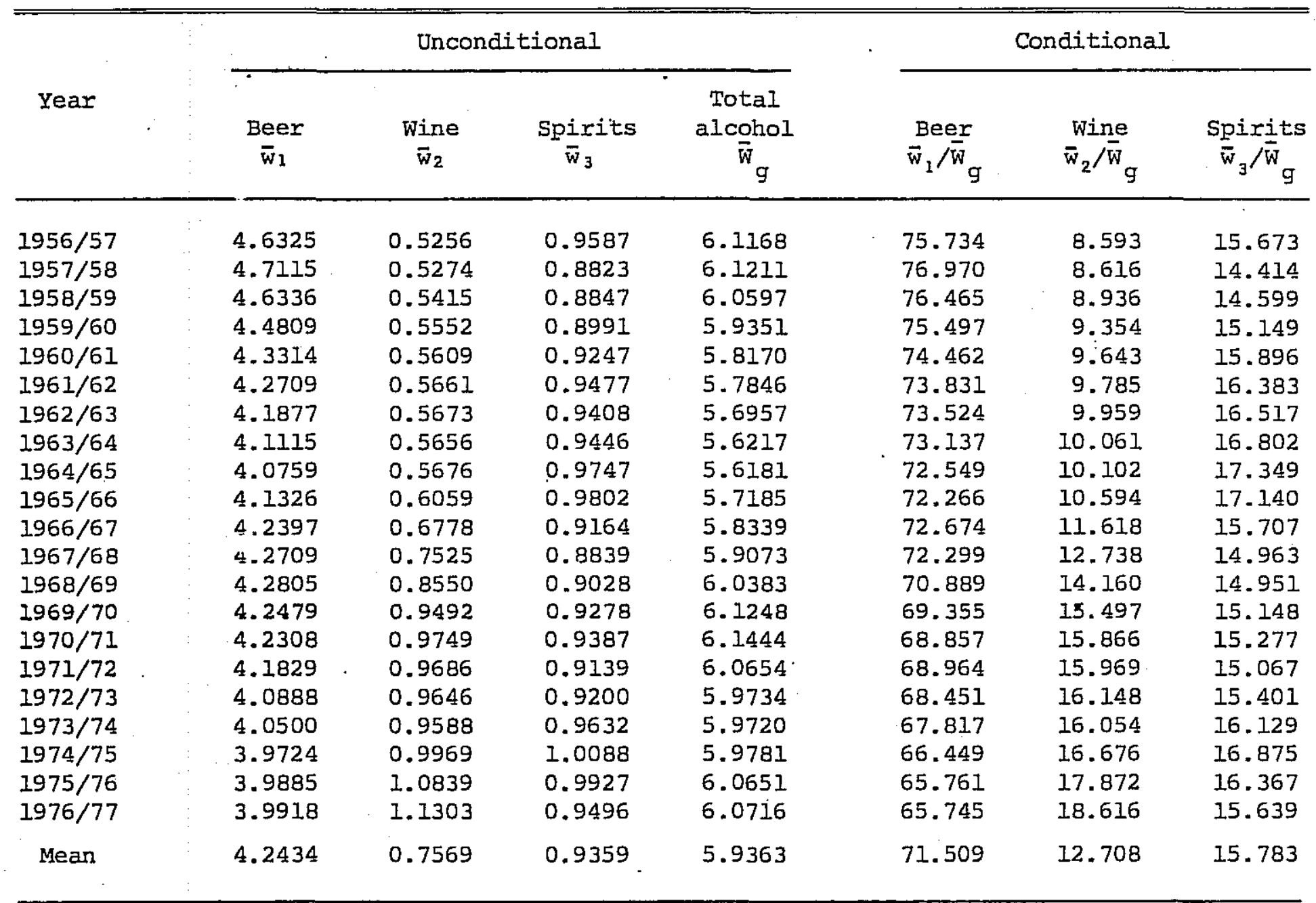

The year 1956/57, for example, refers to the arithmetic averages of the budget shares in 1955/56 and 1956/57. All entries are to be divided by 100 . 
Expenditure on beer, expressed as a percentage of total alcohol expenditure, has fallen by about 10 percentage points to 66 percent in 1976/77 (see the third last column of Table 2). This relative decline in beer expenditure mirrors the dramatic growth of the share of wine in total alcohol, which increased from 8.6 percent in $1956 / 57$ to 18.6 in $1976 / 77$. One of our objectives is to explain this rapid growth in the wine share. The spirits share in total alcohol has been relatively stable at about 16 percent. Further details of the data and sources are given in a separate Appendix, available on request.

Estimates with Total Alcohol Consumption Predetermined

We assume that the total consumption of alcohol $\overrightarrow{\mathrm{W}}_{\mathrm{gt}} \mathrm{DQ}_{\mathrm{gt}}$ and the prices $D_{\mathrm{jt}}$ are predetermined variables and use maximum likelihood to estimate (14) for $i=1,2,3$ subject to the homogeneity and symmetry restrictions (12) and (13). The estimates are given in Table 3.1 constant terms have been added to each equation to take account of trend-like changes in tastes, etc. A preliminary analysis indicated that two constants are needed in each equation, one for the first nine observations $\left(\alpha_{i}\right)$ and one for the remaining twelve $\left(\beta_{i}\right)$. As can be seen, there is a significant trend into wine and out of spirits in the second part of the period. The estimate of $\beta_{i}$ for wine implies that per capita consumption is growing autonomously at an exponential rate of $.53 /\left(\bar{w}_{\text {it }} \times 1000\right)=.53 \times 100 / 1.13 \times 1000=4.7$ percent per annum in $1976 / 77$. The conditional marginal shares are estimated quite precisely and they indicate that when alcohol expenditure increases by one dollar, expenditure on beer rises by 54 cents, wine by 10 cents, with the remaining 37 cents being spent on spirits. All the diagonal elements of the conditional slutsky matrix are negative as they should be, and significant. ${ }^{2}$ The off-diagonal $\pi_{i j}^{g}$ 's are positive, indicating that the three beverages are pairwise substitutes, and only one is insignificantly different from zero. The fit of the equations is satisfactory given that they are in firstdifference form. 
TABLE 3

CONDITIONAI DEMAND EQUATIONS FOR ALCOHOLIC BEVERAGES:

$$
\begin{gathered}
\text { Australida, 1955/56-1976/77 } \\
\bar{w}_{i t}{ }^{D q_{i t}}=\alpha_{i} D_{t}+\beta_{i}\left(1-D_{t}\right)+\theta_{i}^{\prime} \bar{w}_{g t} D Q_{g t}+\sum_{j=1}^{3} \pi_{i j}^{g} D_{j t}+E_{i t}
\end{gathered}
$$

\begin{tabular}{|c|c|c|c|c|c|c|c|c|}
\hline \multirow[b]{2}{*}{ Beverage } & \multicolumn{2}{|c|}{ Constants } & \multirow{2}{*}{$\begin{array}{c}\text { Conditional } \\
\text { marginal } \\
\text { share } \\
\theta_{i}\end{array}$} & \multicolumn{3}{|c|}{ Conditional slutsky coefficients } & \multirow[b]{2}{*}{$\mathrm{R}^{2}$} & \multirow[b]{2}{*}{$\mathrm{DW}$} \\
\hline & $\begin{array}{c}\alpha_{i} \\
\times 1000\end{array}$ & $\begin{array}{c}\beta_{i} \\
\times 1000\end{array}$ & & $\begin{array}{l}\pi_{i 1}^{g} \\
\times 100\end{array}$ & $\begin{array}{l}\pi_{i 2}^{g} \\
\times 100\end{array}$ & $\begin{array}{l}\pi_{i 3}^{g} \\
\times \quad 100\end{array}$ & & \\
\hline Beer & $\begin{array}{c}-.039 \\
(.103)\end{array}$ & $\begin{array}{l}-.107 \\
(.115)\end{array}$ & $\begin{array}{l}.539 \\
(.046)\end{array}$ & $\begin{array}{c}-.464 \\
(.153)\end{array}$ & $\begin{array}{l}.135 \\
(.117)\end{array}$ & $\begin{array}{l}.329 \\
(.101)\end{array}$ & .92 & 2.20 \\
\hline Wine & .066 & $\begin{array}{l}.525 \\
(.084)\end{array}$ & $\begin{array}{l}.095 \\
(.033)\end{array}$ & & $\begin{array}{l}-.300 \\
(.122)\end{array}$ & $\begin{array}{l}.165 \\
(.074)\end{array}$ & .74 & 1.49 \\
\hline Spirits & $\begin{array}{c}-.027 \\
(.100)\end{array}$ & $\begin{array}{r}-.419 \\
(.112)\end{array}$ & $\begin{array}{l}.366 \\
(.044)\end{array}$ & & & $\begin{array}{c}-.494 \\
(.105)\end{array}$ & .78 & 1.66 \\
\hline
\end{tabular}

(Asymptotic standard errors in parentheses)

The variable $D_{t}=1$ for $1956 / 57-1964 / 65$, O otherwise. $R^{2}$ is the squared correlation coefficient'between the actual and predicted values of the dependent variable and thus lies in the range $[0,1]$.

The compatibility of the homogeneity and symmetry restrictions with the data can be verified by means of a likelihood ratio test. The unrestricted version of the model is (14), including constant terms, without the constraints (12) and (13). Asymptotically, minus twice the difference between the log-likelihood values for the restricted and unrestricted models is distributed as $\chi^{2}(3) .{ }^{3}$ The observed value of the test statistic is 4.05 , less than the critical value at the 5 percent level of 7.81 . Thus we are unable to reject homogeneity and symmetry.

Table 4 gives the conditional demand elasticities evaluated at the beginning and end of the sample period, as well as at sample means. At sample means, the conditional income elasticities are $.8, .8$ and 2.3 , for beer, wine and spirits, respectively. This indicates that, within alcohol, beer and wine are necessities and spirits is a strong luxury. Note, however, 
TABLE 4

CONDITIONAL DEMAND ELASTICITIES FOR ALCOHOLIC BEVERAGES:

$$
\text { AUSTRALIA, } 1955 / 56-1976 / 77
$$

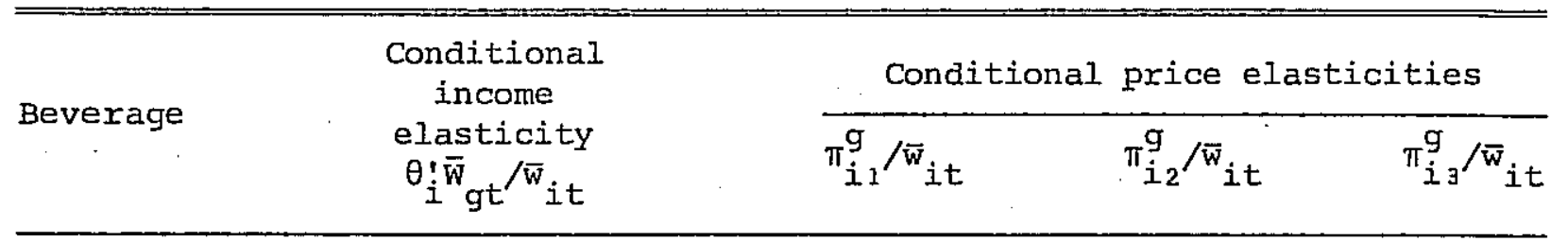

$1956 / 57$

$\begin{array}{lrrrr}\text { Beer } & .71 & -.10 & .03 & .07 \\ \text { Wine } & 1.11 & .26 & -.57 & .31 \\ \text { Spirits } & 2.34 & .34 & .17 & -.52\end{array}$

$1976 / 77$

$\begin{array}{lrrrr}\text { Beer } & .82 & -.12 & .03 & .08 \\ \text { Wine } & .51 & .12 & -.27 & .15 \\ \text { Spirits } & 2.34 & .35 & .17 & -.52\end{array}$

Sample means

$\begin{array}{lrrrr}\text { Beer } & .75 & -.11 & .03 & .08 \\ \text { Wine } & .75 & .18 & -.40 & .22 \\ \text { Spirits } & 2.32 & .35 & .18 & -.53\end{array}$

Based on Table 3 estimates and Table 2 data

- that at the beginning of the period wine has a conditional income elasticity greater than one. All the conditional price elasticities are less than one in absolute value, with the own-price elasticities being $-.1,-.4$ and -.5 (at sample means). As expected, there is only a moderate amount of substitutability between the three beverages.

Estimates with Total Alcohol Consumption Endogenous We now let total alcohol consumption $\overline{\mathrm{W}}_{\mathrm{gt}} \mathrm{DQ}_{\mathrm{gt}}$ become endogenously determined by adding the composite demand equation to the three conditional 
equations. The composite equation in terms of infinitesimal changes is (7). As before, we replace budget shares with their arithmetic averages and infinitesimal logarithmic changes by finite log-changes; and treat the coefficients as constants. Numbering goods such that the alcoholic beverages are the first three, the estimating equation is thus

$$
\overline{\mathrm{w}}_{\mathrm{gt}} \mathrm{DQ} \mathrm{gt}_{\mathrm{gt}}=\theta_{\mathrm{g}} \mathrm{DQ} \mathrm{Q}_{\mathrm{t}}+\phi \theta_{\mathrm{g}}\left(\sum_{i=1}^{3} \theta_{i} \mathrm{Dp}_{i t}-\sum_{j=1}^{\mathrm{n}} \theta_{j} \mathrm{Dp} j \mathrm{jt}\right)+\mathrm{E}_{\mathrm{gt}}{ }^{\prime}
$$

where $\mathrm{DQ}_{t}=\sum_{i=1}^{\mathrm{n}} \overline{\mathrm{w}}_{i t} \mathrm{Dq}_{i t}$ and $\mathrm{E}_{\mathrm{gt}}$ is a serially independent, normally distributed disturbance with a zero mean and a constant variance.

Equations (14) and (15) form a system of four simultaneous equations with endogenous variables $\bar{w}_{i t} D_{i t}(i=1,2,3)$ and $\bar{w}_{g t} D Q g t \cdot$ The variables taken to be predetermined are the prices and $D Q_{t}$. Note that (I5) implies that the only random component of $\bar{W}_{g t}{ }^{D Q} g_{g t}$ is the disturbance $E_{g t}$. Hence, we can treat $\bar{W}_{g t} Q_{g t}$ as predetermined in (14) if $\mathrm{E}_{\mathrm{g}}$ is independent of the disturbance in (14) $\varepsilon_{\text {it }}$. Remarkably, Theil's (1975/76, 1980) theory of rational random behavior implies that these disturbances are independent. Thus, our previous estimates of (14) by itself are consistent under the theory of rational random behavior.

In this sub-section we do not rely on this theory and estimate (14) and (15) simultaneously, allowing the disturbances $\mathrm{E}_{\mathrm{gt}}$ and $\varepsilon_{\text {it }}$ to be correlated. A comparison of the two sets of estimates can be interpreted as an informal test of the theory. In addition, the estimation of (15) allows us to obtain the unconditional demand responses.

The overall Frisch price index in (15) can be written as

$$
\sum_{j=1}^{n} \theta_{j} D p_{j t}=\theta_{g} \sum_{j=1}^{3} \theta_{j} D p_{j t}+\left(1-\theta_{g}\right) \sum_{k=4}^{n} \frac{\theta_{k}}{\sum_{l=4}^{n} \theta_{l}} D p_{k t}
$$

as $\theta_{j}^{\prime}=\theta_{j} / \theta_{g}$ and $\theta_{g}=\sum_{i=1}^{3} \theta_{i}=1-\sum_{\ell=4}^{n} \theta_{\ell}$. In words, the overall Frisch price index is a weighted average of the Frisch indexes for alcohol and all other, the weights being the group marginal shares. The estimation procedure can be simplified by eliminating the marginal shares not involving 
alcohol. We do this by approximating the Frisch index of all other in (16), $\Sigma_{\mathrm{k}=4}^{\mathrm{n}}\left(\theta_{\mathrm{k}} / \Sigma_{\ell=4}^{\mathrm{n}} \theta_{\ell}\right) \mathrm{DP}_{\mathrm{kt}}$, by the change in the consumer price index excluding alcohol (see Appendix) DP ot' so that

$$
\sum_{j=1}^{n} \theta_{j} D p_{j t} \approx \theta_{g} \sum_{j=1}^{3} \theta_{j}^{\prime} D p_{j t}+\left(1-\theta_{g}\right) D P_{o t} .
$$

For estimation we substitute in (15) the right side of (17) for $\sum_{j=1}^{n} \theta_{j} \mathrm{p}_{j t}$. We also approximate the change in real income $\mathrm{DQ}_{t}$ by the difference between the log-change in per capita total consumption expenditure and that of the consumer price index.

The maximum likelihood estimates are given in Table 5. All the estimates for the conditional demand equations are highly consistent with those of Table 3 . This result gives support to the theory of rational random behavior, which allows $\overline{\mathrm{w}}_{\mathrm{gt}} \mathrm{DQ}_{\mathrm{gt}}$ to be treated as predetermined. Looking at the estimates for the composite equation, there is a significant autonomous trend out of alcohol in the first part of the period. The marginal share for the group is highly significant and indicates that a one dollar rise in income leads to a six cent increase in alcohol expenditure. Finally, the value of the income flexibility is quite close to previous estimates. ${ }^{4}$ Testing the homogeneity and symmetry restrictions, as before, gives an observed $\chi^{2}$ value of 5.66, again less than the critical value of $\chi^{2}(3)$ at the 5 percent level.

Table 6 gives the conditional demand elasticities and the income and own-price elasticities for the group. As is to be expected, the conditional elasticities are similar to those of Table 4 . The income elasticity of demand for alcoholic beverages as a whole is 1.0 , while the own-price elasticity is -.6 . 
TABLE 5

CONDITIONAL AND COMPOSITE DEMAND EQUATIONS

FOR ALCOHOLIC BEVERAGES:

AUSTRALIA， 1955/56-1976/77

$$
\begin{gathered}
\bar{w}_{i t} D q_{i t}=\alpha_{i} D_{t}+\beta_{i}\left(I-D_{t}\right)+\theta_{i} \bar{w}_{g t} D_{g t}+\sum_{j=1}^{3} \pi_{i j}^{g} D p_{j t}+\varepsilon_{i t} \\
\vec{w}_{g t} D Q_{g t}=\gamma D_{t}+\lambda\left(I-D_{t}\right)+\theta_{g} D_{t}+\phi \theta_{g}\left(\sum_{i=1}^{3} \theta_{i} D_{i t}-\sum_{j=1}^{n} \theta_{j} D p_{j t}\right)+E_{g t}
\end{gathered}
$$

\begin{tabular}{|c|c|c|c|c|c|c|c|c|}
\hline \multirow[b]{2}{*}{ Beverage } & \multicolumn{2}{|c|}{ Constants } & \multirow{2}{*}{$\begin{array}{c}\text { Conditional } \\
\text { marginal } \\
\text { share } \\
\theta_{i}\end{array}$} & \multicolumn{3}{|c|}{ Conditional slutsky coefficients } & \multirow[b]{2}{*}{$\mathrm{R}^{2}$} & \multirow[b]{2}{*}{ DW } \\
\hline & $\begin{array}{l}\alpha_{i} \\
\times 1000\end{array}$ & $\begin{array}{c}\beta_{i} \\
\times 1000\end{array}$ & & $\begin{array}{l}\pi_{i 1}^{g} \\
\times \quad 100\end{array}$ & $\begin{array}{l}\pi_{i 2}^{g} \\
\times \quad 100\end{array}$ & $\begin{array}{l}\pi_{i 3}^{g} \\
\times \quad 100\end{array}$ & & \\
\hline Beer & $\begin{array}{l}-.065 \\
(.106)\end{array}$ & $\begin{array}{l}-.196 \\
(.115)\end{array}$ & $\begin{array}{l}.590 \\
(.045)\end{array}$ & $\begin{array}{l}-.390 \\
(.145)\end{array}$ & $\begin{array}{l}.150 \\
(.114)\end{array}$ & $\begin{array}{l}.240 \\
(.097)\end{array}$ & .67 & 1.72 \\
\hline Wine & $\begin{array}{l}.062 \\
(.078)\end{array}$ & $\begin{array}{l}.517 \\
(.084)\end{array}$ & $\begin{array}{l}.099 \\
(.035)\end{array}$ & & $\begin{array}{l}-.293 \\
(.124)\end{array}$ & $\begin{array}{l}.144 \\
(.072)\end{array}$ & .68 & 1.24 \\
\hline Spirits & $\begin{array}{l}.003 \\
(.104)\end{array}$ & $\begin{array}{l}-.321 \\
(.111)\end{array}$ & $\begin{array}{l}.311 \\
(.042)\end{array}$ & & & $\begin{array}{l}-.384 \\
(.102)\end{array}$ & .69 & 2.34 \\
\hline $\begin{array}{l}\text { Total } \\
\text { alcohol }\end{array}$ & $\begin{array}{c}\gamma \times 1000 \\
=-.686 \\
(.332)\end{array}$ & $\begin{array}{l}\lambda \times 1000 \\
=.209 \\
(.342)\end{array}$ & $\theta_{\mathrm{g}}=.0576$ & & & $\begin{aligned} \phi= & -.595 \\
& (.130)\end{aligned}$ & .76 & 1.73 \\
\hline
\end{tabular}

(Asymptotic standard errors in parentheses)

$R^{2}$ refers to the reduced form. See notes to Table 3 . 
TABIE 6

CONDITIONAL AND COMPOSITE DEMAND ELASTICITIES

FOR ALCOHOLIC BEVERAGES :

AUSTRALIA, . 1955/56-1976/77

\begin{tabular}{|c|c|c|c|c|c|}
\hline \multirow{2}{*}{ Beverage } & \multirow{2}{*}{$\begin{array}{c}\text { Conditional } \\
\text { income } \\
\text { elasticity } \\
\theta ! \bar{w}_{\text {gt }} / \bar{w}_{i t}\end{array}$} & Conditional price & elasticities & \multirow{2}{*}{$\begin{array}{c}\text { Composite } \\
\text { income } \\
\text { elasticity } \\
\theta_{\mathrm{g}} / \overline{\mathrm{w}}_{\mathrm{gt}}\end{array}$} & \multirow{2}{*}{$\begin{array}{c}\text { Composite } \\
\text { own-price } \\
\text { elastici.ty } \\
\phi \theta_{\mathrm{g}} / \overline{\mathrm{W}}_{\mathrm{gt}}\end{array}$} \\
\hline & & $\pi_{i l}^{g} / \bar{w}_{i t}$ & $\pi_{i j}^{g} / \bar{w}_{i t}$ & & \\
\hline
\end{tabular}

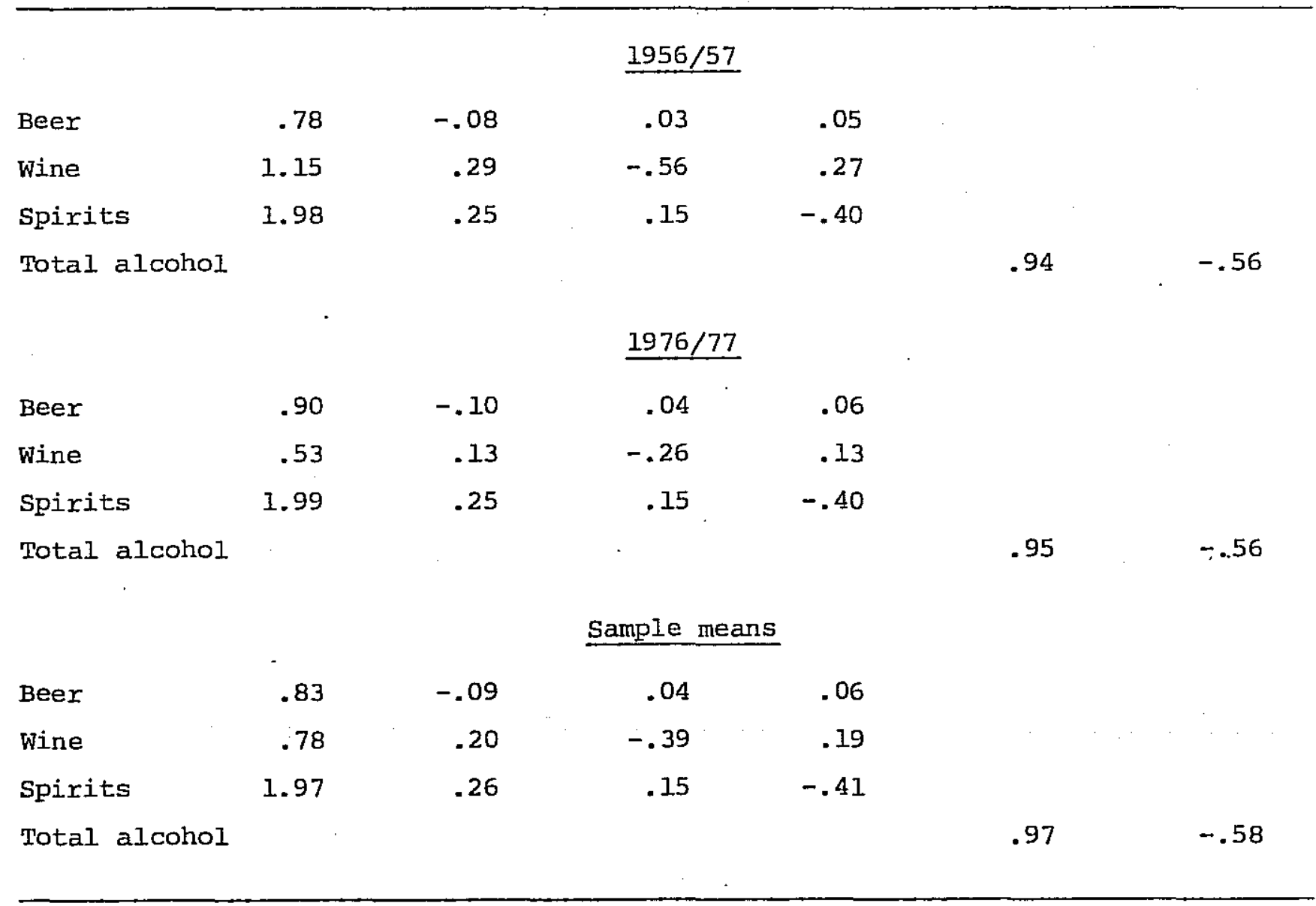

Based on Table 5 estimates and Table 2 data 
The Unconditional Demand Responses

The conditional demand equation (14) depends on total alcohol consumption and the prices of the three beverages. Accordingly, the conditional slutsky coefficient $\pi_{i j}^{g}$ measures the effect of a change in the price of alcoholic beverage $j$ on the consumption of beverage $i$ with total alcohol consumption held constant. From equation (15), this total also depends on the price of $j$. Thus a change in $p_{j}$ has a direct effect on $i$, via the conditional demand equation, and an indirect effect via the composite demand equation. These two effects can be combined to give the total eifect by substituting the right side of (15) for $\overline{\mathrm{w}}_{\mathrm{gt}} \mathrm{DQ}_{\mathrm{gt}}$ in (14). This yields

$$
\bar{w}_{i t} \mathrm{Dq}_{i t}=\theta_{i} \mathrm{DQ}_{t}+\sum_{j=1}^{3} \pi_{i j} \mathrm{DP}_{j t}+\pi_{i 0} \mathrm{DP}_{0 t}+\eta_{i t}
$$

where

$$
\theta_{i}=\theta_{g} \theta i
$$

is the unconditional marginal share of $i$;

$$
\pi_{i j}=\pi_{i j}^{g}+\phi \theta_{g}\left(1-\theta_{g}\right) \theta_{i} \theta_{j} . \quad \pi_{i 0}=-\phi \theta_{g}\left(1-\theta_{g}\right) \theta_{i}
$$

are unconditional slutsky coefficients; and $\eta_{i t}=\varepsilon_{i t}+\theta_{i}^{E_{g t}}$. In deriving (18) we have used the right side of (17) to substitute for $\sum_{j=1}^{n} \theta_{j} p_{j t}$ in (15). From (18) it can be seen that the unconditional income and price elasticities are $\theta_{i} / \bar{w}_{i t}, \cdot \pi_{i j} / \bar{w}_{i t}$ and $\pi_{i 0} / \bar{w}_{i t} \cdot$

We use the Table 5 estimates to evaluate (19) and (20) for $i, j=1,2,3$. The results are given in Table 7 . Thus the direct and indirect effects of a one dollar rise in income is to increase expenditure on beer by 3.4 cents, wine by .6 cents and spirits by 1.8 cents. All the own-slutsky coefficients are estimated quite precisely and each is more negative than the corresponding conditional coefficient of Table 5. The reason is that an increase in the price of beverage $i$ lowers total alcohol consumption which also lowers the consumption of $i$, as the estimate of $\theta_{i}$ is positive for each $i$. This 
TABLE 7

UNCONDITIONAL DEMAND EQUATIONS FOR ALCOHOLIC BEVERAGES:

$$
\begin{gathered}
\text { AUSTRAIIA, 1955/56-1976/77 } \\
\bar{w}_{i t} D q_{i t}=\delta_{i} D_{t}+\psi_{i}\left(I-D_{t}\right)+\theta_{i} D_{t}+\sum_{j=1}^{3} \pi_{i j} D p_{j t}+\pi_{i 0} D P_{0 t}+\eta_{i t}
\end{gathered}
$$

\begin{tabular}{|c|c|c|c|c|c|c|c|}
\hline \multirow[b]{2}{*}{ Beverage } & \multicolumn{2}{|c|}{ Constants } & \multirow{2}{*}{$\begin{array}{c}\text { Marginal } \\
\text { share } \\
\theta_{i}\end{array}$} & \multicolumn{4}{|c|}{ Slutsky coefficients } \\
\hline & $\begin{array}{c}\delta_{i} \\
\times 1000\end{array}$ & $\begin{array}{c}\psi_{i} \\
\times 1000\end{array}$ & & $\begin{array}{l}\pi_{i 1} \\
\times 100\end{array}$ & $\begin{array}{l}\pi_{i 2} \\
\times \quad 100\end{array}$ & $\begin{array}{l}\pi_{i 3} \\
\times \quad 100\end{array}$ & $\begin{array}{l}\pi_{i 0} \\
\times \quad 100\end{array}$ \\
\hline Beer & $\begin{array}{l}-.469 \\
(.236)\end{array}$ & $\begin{array}{l}-.073 \\
(.235)\end{array}$ & $\begin{array}{l}.0340 \\
(.0062)\end{array}$ & $\begin{array}{r}-1.514 \\
(.299)\end{array}$ & $\begin{array}{c}-.039 \\
(.125)\end{array}$ & $\begin{array}{l}-.353 \\
(.146)\end{array}$ & $\begin{array}{l}1.906 \\
(.377)\end{array}$ \\
\hline Wine & $\begin{array}{l}-.006 \\
(.092)\end{array}$ & $\begin{array}{l}.537 \\
(.089)\end{array}$ & $\begin{array}{c}.0057 \\
(.0023)\end{array}$ & & $\begin{array}{l}-.325 \\
(.132)\end{array}$ & $\begin{array}{c}.044 \\
(.080)\end{array}$ & $\begin{array}{l}.319 \\
(.132)\end{array}$ \\
\hline spirits & $\begin{array}{r}-.210 \\
(.139)\end{array}$ & $\begin{array}{l}-.256 \\
(.139)\end{array}$ & $\begin{array}{l}.0179 \\
(.0037)\end{array}$ & & & $\begin{array}{l}-.697 \\
(.130)\end{array}$ & $\begin{array}{l}1.006 \\
(.202)\end{array}$ \\
\hline
\end{tabular}

(Asymptotic standard errors in parentheses)

The estimates from Table 5 are used in equations (19) and (20) to obtain the (unconditional) marginal shares and slutsky. coefficients. The constant term $\delta_{i}$ is defined as $\alpha_{i}+\theta_{i}^{i} \gamma$, with estimates taken from Table 5; and similarly for $\psi_{i}$.

see notes to Table 3 .

negative indirect effect is then added to the conditional slutsky coefficient $\pi_{i i}^{g}(<0)$ to give an unconditional coefficient $\pi_{i i}$ larger in absolute value than $\pi_{i 1}^{g}$. For a similar reason the estimates of $\pi_{12}$ and $\pi_{13}$ are negative, indicating that beer is an unconditional complement for wine and spiriț, whereas these beverages are conditional substitutes $\left(\pi_{12}^{g}, \pi_{13}^{g}>0 ;\right.$ see Table 5). Finally, each of the three beverages is a substitute for all other goods.

Table 8 gives the unconditional elasticities. As the income elasticity for the group is about unity (see Table 6), the unconditional income elasticities given in Table 8 are quite close to the corresponding conditional elasticities. For the reason given above, the own-price 
elasticities are substantially larger (in absolute value) than those of Table 6. At sample means, the unconditional own-price elasticities are $-.4,-.4$ and -.7 for beer, wine and spirits, respectively.

\section{TABLE 8}

UNCONDITIONAL DEMAND ELASTICITIES FOR ALCOHOLIC BEVERAGES:

$$
\text { AUSTRALIA, 1955/56 - 1976/77 }
$$

\begin{tabular}{|c|c|c|c|c|c|}
\hline \multirow{2}{*}{ Beverage } & \multirow{2}{*}{$\begin{array}{c}\text { Income } \\
\text { elasticity } \\
\theta_{i} / \vec{w}_{i t}\end{array}$} & \multicolumn{4}{|c|}{ Price elasticities } \\
\hline & & $\pi_{i l} / \vec{w}_{i t t}$ & $\pi_{i 2} / \bar{w}_{i t}$ & $\pi_{i 3} / \bar{w}_{i t}$ & $\pi_{i 0} / \bar{w}_{i t}$ \\
\hline
\end{tabular}

\section{$1956 / 57$}

$\begin{array}{lrrrrr}\text { Beer } & .73 & -.33 & -.01 & -.08 & .41 \\ \text { Wine } & 1.08 & -.07 & -.62 & .08 & .61 \\ \text { Spirits } & 1.87 & -.37 & .05 & -.73 & 1.05\end{array}$

\section{$1976 / 77$}

$\begin{array}{lrrrrr}\text { Beer } & .85 & -.37 & -.01 & -.09 & .48 \\ \text { Wine } & .50 & -.03 & -.29 & .04 & .28 \\ \text { Spirits } & 1.89 & -.37 & .05 & -.73 & 1.06\end{array}$

Sample means

$\begin{array}{lrrrrr}\text { Beer } & .80 & -.36 & -.01 & -.08 & .45 \\ \text { Wine } & .75 & -.05 & -.43 & .06 & .42 \\ \text { Spirits } & 1.91 & -.38 & .05 & -.74 & 1.07\end{array}$

Based on Table 7 estimates and Table 2 data. 


\section{WHY HAS WINE GROWN SO RAPIDLY?}

As indicated in the previous section, wine consumption per capita grew by 4.5 percent per annum over our sample period; and the share of wine in total alcohol expenditure increased by 10 percentage points. In this section we analyse the reasons for this rapid growth by using the demand equations to (i) decompose the growth into a number of components and (ii) simulate alcohol consumption under several different scenarios.

\section{A Decomposition of the Change in the Budget Share}

Recalling that the $i$ th budget share is defined as $w_{i}=\dot{p}_{i} q_{i} / M$, its change is $d w_{i}=w_{i} d\left(\log p_{i}\right)+w_{i} d\left(\log q_{i}\right)-w_{i} d(\log M) \cdot$ This can be expressed in terms of the relative price of $i$ and real income by adding and subtracting from the right side the Divisia cost of living index $\mathrm{d}(\log P)=\Sigma_{i=1}^{n} w_{i} d\left(\log p_{i}\right)$. This gives

$$
d w_{i}=w_{i} d\left(\log \frac{p_{i}}{p}\right)+w_{i} d\left(\log q_{i}\right)-w_{i} d(\log q) \text {, }
$$

where $d\left(\log \frac{p_{i}}{P}\right)=d\left(\log p_{i}\right)-d(\log P)$ is the change in the relative price of $i$ and $d(\log Q)=d(\log M)-d(\log P)=\sum_{i=1}^{n} w_{i} d\left(\log q_{i}\right)$ is the change in real income.

Equation (21) states that $d w_{i}$ is made up of relative price, quantity and real income components. From the consumer's viewpoint prices and income are given, while the quantity demanded ist to be determined. Thus we use the demand equation (I) to express the quantity component in terms of income and relative prices,

$$
d w_{i}=\left(\theta_{i}-w_{i}\right) d(\log Q)+\sum_{j=1}^{n} v_{i j} d\left(\log \frac{p_{j}}{p^{i}}\right)+w_{i} d\left(\log \frac{p_{i}}{p}\right) .
$$

Thus a rise in income causes the budget share of $i$ to increase if the marginal share $\left(\theta_{i}\right)$ exceeds the average share $\left(w_{i}\right) ;$ i.e. if this good is a 
luxury. The second component on the right of (22) is the price substitution term, which gives the effect of changes in relative prices on $w_{i}$ via $q_{i}$. The final term is the direct effect of the relative price of $i$ on the budget share. 5

To apply (22) to the finite-change data for alcoholic beverages, we use the right side of equation (18) to substitute for the quantity component in (21). This gives

$$
\begin{gathered}
\Delta w_{i t}=\left(\theta_{i}-\bar{w}_{i t}\right) D q_{t}+\sum_{j=1}^{3} \pi_{i j} D p_{j t}+\pi_{i 0} D P_{0 t}+\bar{w}_{i t}\left(D p_{i t}-D P_{t}\right) \\
+\eta_{i t}+o_{3},
\end{gathered}
$$

where $\Delta w_{i t}=w_{i t}-w_{i, t-1}$ and $o_{3}$ is a remainder term of third degree (Theil, 1975/76, pp. 37-40, 215). Note that (12) and (20) imply $\sum_{j=1}^{3} \pi_{i j}+\pi_{i 0}=0$, which is a reflection of demand homogeneity. We use this to deflate the absolute prices in (23) $\mathrm{Dp}_{j t}$ and $\mathrm{DP}_{\text {ot }}$ by $\mathrm{DP}_{t}$ to give

$$
\begin{gathered}
\Delta w_{i t}=\left(\theta_{i}-\bar{w}_{i t}\right) D Q_{t}+\sum_{j=1}^{3} \pi_{i j}\left(D p_{j t}-D P_{t}\right)+\pi_{i 0}\left(D P_{0 t}-D P_{t}\right) \\
+\bar{w}_{i t}\left(D p_{i t}-D P_{t}\right)+\eta_{i t}+0_{3} .
\end{gathered}
$$

To evaluate (24) we use the estimates given in Table 7 and the log-change in the consumer price index for $\mathrm{DP}_{t}$. The constant term in the demand equation $\delta_{i} D_{t}+\psi_{i}\left(I-D_{t}\right)$ means that this is an additional component of $\Delta w_{i}$. The results are given in Tables 9-11. Looking at Table 9, on average the budge share of beer fell by $2.94 / 100$ percentage points per annum. The shift in prefexences away from beer accounts for 2.43 of this. The growth in real income, together with the fact that beer is a necessity, accounts for 1.91 of the fall. The rise in the relative price of beer accounts for .75 , while the other relative prices have a negligible effect. Finally, offsetting the fall in the beer share is the direct relative price component of 2.19. The conclusion which emerges is that the shift in preferences away from beer and the growth in real income are the two most important reasons for the decline in the budget share of beer. 
TABLE 10

DECOMPOSIIION OF CHANGE IN BUDGET SHARE OF WINE: AUSTRALIA, 1955/56 - 1976/77

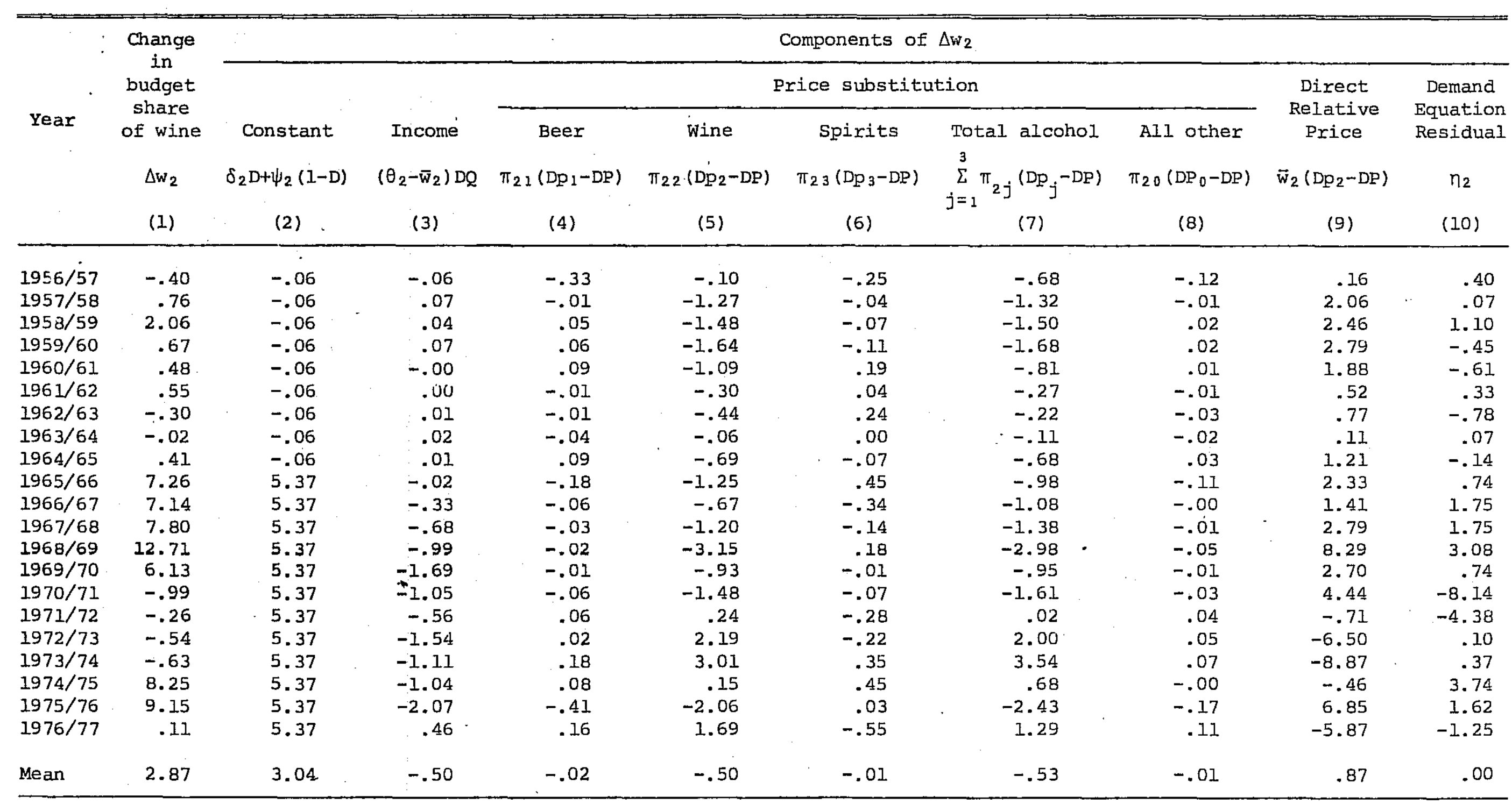

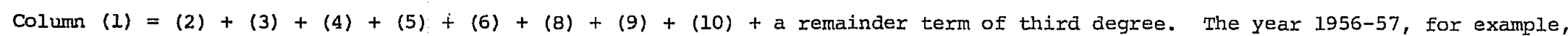
refers to the transition from 1955-56 to 1956-57. All entries are to be divided by 10000 . 
TABIE 11

DECOMPOSITION OF CHANGE IN BUDGET SHARE OF SPIRITS: AUSTRALIA, 1955/56 - 1976/77

\begin{tabular}{|c|c|c|c|c|c|c|c|c|c|c|}
\hline \multirow[b]{3}{*}{ Year } & \multirow{3}{*}{$\begin{array}{c}\text { Change } \\
\text { in } \\
\text { budget } \\
\text { share } \\
\text { of } \\
\text { spirits } \\
\Delta w_{3}\end{array}$} & \multicolumn{9}{|c|}{ Components of $\Delta w_{3}$} \\
\hline & & \multirow[b]{2}{*}{$\begin{array}{c}\text { Constant } \\
\delta_{3} D+\psi_{3}(1-D)\end{array}$} & \multirow[b]{2}{*}{$\begin{array}{c}\text { Income } \\
\left(\theta_{3}-\bar{w}_{3}\right) \mathrm{DQ}\end{array}$} & \multicolumn{5}{|c|}{ Price substitution } & \multirow{2}{*}{ 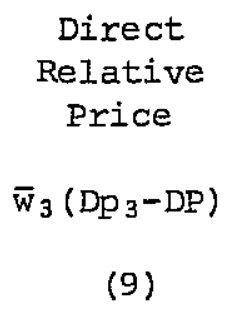 } & \multirow{2}{*}{$\begin{array}{l}\text { Demand } \\
\text { Equation } \\
\text { Residual } \\
\eta_{3} \\
\text { (10) }\end{array}$} \\
\hline & & & & $\begin{array}{c}\text { Beer } \\
\pi_{31}\left(D_{1}-D P\right) \\
(4)\end{array}$ & $\begin{array}{c}\text { Wine } \\
\pi_{32}\left(D_{2}-D P\right) \\
(5)\end{array}$ & $\begin{array}{c}\text { Spirits } \\
\pi_{33}\left(D p_{3}-D P\right) \\
(6)\end{array}$ & $\begin{array}{c}\text { Total alcohol } \\
\sum_{j=1}^{3} \pi_{3 j}\left(D p_{j}-D P\right)\end{array}$ & $\begin{array}{c}\text { All other } \\
\pi_{30}\left(D P_{0}-D P\right) \\
\text { (8) }\end{array}$ & & \\
\hline $1956 / 57$ & -13.98 & -2.10 & -1.20 & -3.01 & .01 & 3.96 & .96 & -.37 & -5.45 & -5.92 \\
\hline $1957 / 58$ & -1.30 & -2.10 & 1.49 & -.09 & .17 & .68 & .76 & -.03 & -.86 & -.49 \\
\hline $1958 / 59$ & 1.77 & -2.10 & 1.29 & .42 & .20 & 1.09 & 1.72 & .05 & -1.39 & 2.08 \\
\hline $1959 / 60$ & 1.12 & -2.10 & 4.18 & .58 & .22 & 1.73 & 2.53 & .07 & -2.23 & -1.32 \\
\hline $1960 / 61$ & 4.00 & -2.10 & -.29 & .78 & .15 & -3.07 & -2.14 & .04 & 4.07 & 4.44 \\
\hline $1961 / 62$ & .62 & -2.10 & .41 & -.09 & .04 & -.60 & -.66 & -.03 & .82 & 2.18 \\
\hline $1962 / 63$ & -2.02 & -2.10 & 4.18 & -.13 & .06 & -3.79 & -3.86 & -.08 & 5.11 & -5.21 \\
\hline $1963 / 64$ & 2.79 & -2.10 & 4.03 & -.38 & .01 & -.00 & -.38 & -.05 & .01 & 1.22 \\
\hline $1964 / 65$ & 3.25 & -2.10 & 1.79 & .82 & .09 & 1.19 & 2.10 & .11 & -1.66 & 3.06 \\
\hline $1965 / 66$ & -2.18 & -2.56 & .39 & -1.62 & .17 & -7.10 & -8.55 & -.33 & 9.98 & -1.16 \\
\hline $1966 / 67$ & -10.59 & -2.56 &.$\quad 2.70$ & -.58 & .09 & 5.37 & 4.88 & -.01 & -7.06 & -8.49 \\
\hline $1967 / 68$ & 4.10 & -2.56 & .3 .37 & -.31 & .16 & 2.26 & 2.12 & -.04 & -2.87 & 4.05 \\
\hline $1968 / 69$ & -.32 & -2.56 & 3.08 & -.16 & .43 & -2.92 & -2.65 & -.15 & 3.78 & -1.83 \\
\hline $1969 / 70$ & 5.32 & -2.56 & 3.85 & -.11 & .13 & .21 & .22 & -.04 & -.28 & 4.11 \\
\hline $1970 / 71$ & -3.12 & -2.56 & $\rightarrow 2.22$ & -.58 & .20 & 1.12 & .74 &.- .11 & -1.50 & -1.86 \\
\hline $1971 / 72$ & -1.85 & -2.56 & 1.23 & .52 & -.03 & 4.41 & 4.90 & .14 & -5.78 & .18 \\
\hline $1972 / 73$ & 3.07 & -2.56 & 3.39 & .22 & -.30 & 3.48 & 3.41 & .15 & -4.60 & 3.31 \\
\hline $1973 / 74$ & 5.58 & -2.56 & 2.37 & 1.61 & -.41 & -5.60 & -4.40 & .21 & 7.73 & 2.24 \\
\hline $1974 / 75$ & 3.54 & -2.56 & 1.91 & .75 & -.02 & -7.11 & -6.38 & -.01 & 10.30 & .27 \\
\hline $1975 / 76$ & -6.76 & -2.56 & 3.22 & -3.70 & .28 & -.52 & -3.94 & -.53 & .74 & -3.70 \\
\hline $1976 / 77$ & -1.87 & -2.56 & -.69 & 1.41 & -.23 & 8.75 & 9.93 & .36 & -11.92 & 3.01 \\
\hline Mean & -.42 & -2.36 & 2.04 & -.17 & .07 & .17 & .06 & -.03 & -.15 & .01 \\
\hline
\end{tabular}

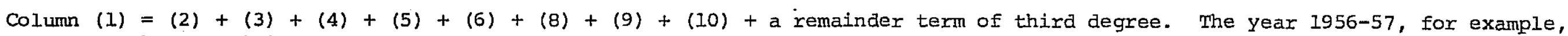
refers to the transition from 1955-56 to 1956-57. All entries are to be divided by 10000 . 
As can be seen from Table 10, the most important component of growth in the wine share on average is the shift in preferences toward wine. This is then followed by the direct relative price component, caused by the price of wine rising more rapidly than the CPI. Offsetting these two terms are the effects due to growth in real income and own-price substitution. For spirits (Table ll) on average the growth in income has the effect of almost offsetting the negative shift in preferences; and the other components are quite small.

\section{Simulation of Alcohol Consumption}

In this sub-section we attempt to isolate the key factors responsible for the rapid growth of wine consumption by using the demand model for counterfactual simulations. We simulate alcohol consumption with (i) alcohol tax rates held constant; (ii) a wine tax rate equal to the beer tax rate; and (iii) no constant terms in the demand equations. These simulations answer the question to what extent the growth in wine is due to (i) changes in all alcohol taxes; (ii) the fact that beer is subject to a substantial tax, while wine is not; and (iii) trend-like changes in tastes toward wine.

Table 12 gives the data on alcohol taxes, in terms of both revenue and tax rates. ${ }^{6}$ As can be seen, although beer represents the most important source of revenue, its tax rate has almost halved over this period (from 117 to 63 percent). Aside from the early 1970s, the tax on wine is negligible, while the tax rate for spirits has increased.

We simulate consumption with the tax rates held constant at their 1955/56 values of 117 percent, 0 and 38 percent for beer, wine and spirits, respectively. With $p_{i}$ the post-tax price of $i, p_{i}^{0}$ the pre-tax price and $t_{i}$ the tax rate, we have $p_{i t}=\left(1+t_{i t}\right) p_{i t}^{0}$, so that $D p_{i t}=D\left(I+t t_{i t}\right)+D p_{i t}^{0}$, where $D$ is the log-change operator (as before). Accordingly, we can simulate the constant tax rates by replacing in the 
TABIE 12

ALCOHOL TAXES: AUSTRALIA, 1955/56-1976/77

Tax revenues

(Dollars per capita)

Year

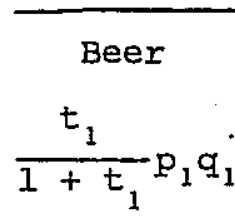

18.33
21.72
21.77
21.17
21.59
21.51
21.41
21.72
22.45
23.17
26.34
27.43
28.45
29.26
29.88
30.08
30.53
31.65
34.31
34.81
50.17
53.23
28.23

$1955 / 56$

$1956 / 57$

$1957 \% 58$

$1958 / 59$

$1959 / 60$

$1960 / 61$

$1961 / 62$

$1962 / 63$

$1963 / 64$

$1964 / 65$

$1965 / 66$

$1966 / 67$

$1967 / 68$

$1968 / 69$

$1969 / 70$

$1970 / 71$

$1971 / 72$

$1972 / 73$

$1973 / 74$

$1974 / 75$

$1975 / 76$

$1976 / 77$

Mean

\begin{tabular}{ccc} 
Wine & Spirits & $\begin{array}{c}\text { Total } \\
\text { Alcohol }\end{array}$ \\
$t_{2}$ & $t_{3}$ & $t_{i}$ \\
\hline$+t_{2}$ & $p_{2} q_{2}$ & $\sum_{i=1}^{3} \frac{1}{I+t_{3}} p_{i} q_{i}$
\end{tabular}

0

0

.01

.01

.01

.01

.01

.02

.02

.02

.03

.04

.05

.75

.96

.32

.09

.11

.15

.18

.13

2.14
2.27
2.27
2.39
2.63
2.64
2.67
2.59
2.78
3.00
3.31
3.67
4.09
3.96
4.41
4.38
4.63
5.23
7.70
10.73
11.83
13.40
4.67

20.47

23.99

24.04

23.56

24.23

24.16

24.09

24.32

25.24

26. 19

29.67

31. 12

32.57

33.26

34.34

35.21

36.12

37.20

42.10

45.65

62.15

66.81

33.02
Tax rates $\times 100$

(Percentages of pre-tax prices)

Beer Wine Spirits

t

$t_{2}$

$t_{3}$

$\begin{array}{rrr}117.198 & 0 & 38.351 \\ 141.132 & 0 & 48.401 \\ 137.090 & 0 & 47.588 \\ 126.086 & 0 & 47.704 \\ 124.296 & .201 & 48.524 \\ 119.236 & .192 & 43.421 \\ 117.250 & .189 & 43.133 \\ 116.272 & .180 & 39.602 \\ 111.358 & .170 & 38.773 \\ 108.372 & .320 & 37.927 \\ 119.674 & .273 & 42.436 \\ 112.929 & .232 & 53.891 \\ 104.365 & .292 & 53.254 \\ 97.793 & .316 & 46.589 \\ 90.491 & .343 & 44.862 \\ 79.073 & 5.064 & 41.995 \\ 74.356 & 6.057 & 41.749 \\ 68.654 & 1.767 & 41.213 \\ 61.598 & .425 & 53.584 \\ 50.353 & .400 & 64.601 \\ 64.761 & .426 & 64.965 \\ 62.615 & .452 & 67.507 \\ 100.225 & .786 & 47.730 \\ & & \end{array}$


demand equations the observed price log-change $D_{i t}$ with $D p_{i t}-D\left(1+t_{i t}\right)$ ' which is the price-change purged of its tax-change component. Using equation (18), the simulated quantity log-change is

$\mathrm{Dq}_{i t}^{\mathrm{s}}=\left(\theta_{i} / \bar{w}_{i t}\right) \mathrm{DQ} Q_{t}+\sum_{j=1}^{3}\left(\pi_{i j} / \bar{w}_{i t}\right)\left[\mathrm{DP}_{j t}-\mathrm{D}\left(I+t_{j t}\right)\right]+\left(\pi_{i 0} / \bar{w}_{i t}\right) \mathrm{DP}_{0 t}+\eta_{i t} / \bar{w}_{i t}$. Subtracting from this the observed quantity log-change $\mathrm{Dq}_{i t}$ and using (18) gives

$$
D q_{i t}^{s}-D q_{i t}=-\sum_{j=1}^{3}\left(\pi_{i j} / \bar{w}_{i t}\right) D\left(1+t_{j t}\right)
$$

Converting from changes to levels, the simulated quantity is

$$
q_{i t}^{s}=\exp \left(D q_{i t}+\log q_{i, t-1}^{s}\right)
$$

Finally, to evaluate (25) we use the estimates given in Table 7 .

The results of this simulation are given in the first three columns of Table 13 (for changes) and in columns 4-6 of Table 14 (levels). As the observed tax rate for beer fell over this period and that for spirits rose, the constant tax rate policy causes beer consumption to be lower than otherwise and spirits to be higher. By 1976/77. simulated per capita consumption is 125 . Iitres, 13.4 litres and 3.23 litres for beer, wine and spirits (see Table 14). Accordingly, this tax package causes beer consumption to be $(124.57-136.14) / 136.14=8.5$ percent Iower than otherwise, wine to be $(13.3616-13.6533) / 13.6533=2.1$ percent lower and spirits to be $(3.2300-3.1663) / 3.1663=2.0$ percent higher. The reasons for the lower consumption of wine are (i) that it is an unconditional complement for beer (see Table 7) and in the simulation we increase the price of beer; and (ii) wine and spirits are unconditional substitutes and the price of spirits increases less rapidly in the simulation.

The conclusion from this simulation is that although changes in all alcohol taxes have contributed to the rapid growth of wine, this contribution is a small component of the overall growth. 
SIMULATION OF CONSUMPTION OF ALCOHOLIC BEVERAGES: AUSTRALIA, 1955/56 - 1976/77

(Simulated quantity log-changes minus actual)

\begin{tabular}{|c|c|c|c|c|c|c|c|c|c|c|}
\hline \multirow{2}{*}{ Year } & \multicolumn{3}{|c|}{ Alcohol tax rates held constant } & \multicolumn{3}{|c|}{ Wine tax rate equal to the beer tax rate } & \multicolumn{4}{|c|}{ No constant terms in demand equations } \\
\hline & Beer & Wine & Spirits & Beer & Wine & Spirits & & Beer & Wine & Spirits \\
\hline $1956 / 57$ & 3.95 & .19 & 8.95 & -.74 & -54.43 & 4.04 & & 1.01 & .11 & 2.19 \\
\hline $1957 / 58$ & -.58 & -.08 & -1.11 & .01 & 1.04 & -.08 & & 1.00 & .11 & 2.38 \\
\hline $1958 / 59$ & -1.55 & -.35 & -1.83 & .04 & 2.85 & -.24 & & 1.01 & .11 & 2.37 \\
\hline $1959 / 60$ & -.22 & .02 & .11 & .01 & .58 & -.05 & & 1.05 & .11 & 2.34 \\
\hline $1960 / 61$ & -1.08 & .11 & -3.51 & .02 & 1.32 & -.11 & & 1.08 & .11 & 2.27 \\
\hline $1961 / 62$ & -.34 & -.05 & -.49 & .01 & .52 & -.04 & & 1.10 & .11 & 2.22 \\
\hline $1963 / 64$ & -.90 & -.12 & -1.30 & .02 & 1.31 & -.11 & . & 1.14 & .11 & 2.22 \\
\hline $1964 / 65$ & -.58 & .04 & -.96 & .02 & .90 & -.07 & & 1.15 & .11 & 2.15 \\
\hline $1965 / 66$ & 2.21 & .08 & 4.19 & -.05 & -2.86 & .24 & & .18 & -8.86 & 2.61 \\
\hline $1966 / 67$ & -.47 & -.70 & 4.68 & .03 & 1.48 & -.15 & & .17 & -7.92 & 2.79 \\
\hline $1967 / 68$ & -1.49 & -.16 & -1.97 & .04 & 1.80 & -.21 & & .17 & -7.14 & 2.90 \\
\hline $1968 / 69$ & -1.52 & .09 & -4.71 & .03 & 1.25 & -.16 & & .17 & -6.28 & 2.84 \\
\hline $1969 / 70$ & -1.44 & -.09 & -2.32 & .03 & 1.30 & -.18 & & .17 & -5.66 & 2.76 \\
\hline $1970 / 71$ & -2.34 & 1.38 & -4.02 & .10 & 3.59 & -.51 & & .17 & -5.51 & 2.73 \\
\hline $1971 / 72$ & -.97 & .22 & -1.21 & .03 & 1.21 & -.17 & & .17 & -5.54 & 2.80 \\
\hline $1972 / 73$ & -1.30 & $-1.5 I$ & -1.37 & -.01 & -.27 & .04 & & .18 & -5.57 & 2.78 \\
\hline $1974 / 75$ & -2.13 & -.60 & 2.26 & .07 & 2.34 & -.31 & & .18 & -5.39 & 2.54 \\
\hline $1975 / 76$ & 3.49 & .33 & 3.41 & -.09 & -2.74 & .40 & & .18 & -4.95 & 2.58 \\
\hline $1976 / 77$ & -.36 & -.10 & .63 & .01 & .38 & -.06 & & .18 & -4.75 & 2.70 \\
\hline Mean & -.42 & -.10 & .09 & -.02 & -1.77 & .10 & & .56 & -3.44 & 2.53 \\
\hline
\end{tabular}

The entries are $D q_{i t}^{S}-D q_{i t}$, where $D q_{i t}^{S}$ is the simulated log-change in the quantity consumed per capita of $i$ and $D_{i t}$ is the actual log-change. The year 1956/57, for example, refers to the transition from $1955 / 56$ to $1956 / 57$. All entries are to be divided by 100 . 
TABLE 14

ACTUAL AND SIMULATED CONSUMPTION OF ALCOHOLIC BEVERAGES: AUSTRALIA, $1955 / 56$ - $1976 / 77$

(Litxes per capita)

\begin{tabular}{|c|c|c|c|c|c|c|c|c|c|c|c|c|}
\hline \multirow[t]{2}{*}{ Year } & \multicolumn{3}{|c|}{ Actual consumption } & \multicolumn{3}{|c|}{$\begin{array}{l}\text { Simulated consumption with } \\
\text { alcohol tax rates held constant }\end{array}$} & \multicolumn{3}{|c|}{$\begin{array}{l}\text { Simulated consumption with } \\
\text { wine tax rate equal to the } \\
\text { beer tax rate }\end{array}$} & \multicolumn{3}{|c|}{$\begin{array}{c}\text { Simulated consumption with } \\
\text { no constant terms in demand } \\
\text { equations }\end{array}$} \\
\hline & Beer & wine & Spirits & Beer & Wine & Spirits & Beer & Wine & Spirits & Beer & Wine & Spirits \\
\hline $1955 / 56$ & 105.98 & 5.3374 & 1.9977 & 105.98 & 5.3374 & 1.9977 & 105.98 & 5.3374 & 1.9977 & 105.98 & 5.3374 & 1.9977 \\
\hline $1956 / 57$ & 100.45 & 5.2084 & 1.7999 & 104.50 & 5.2182 & 1.9684 & 99.71 & 3.0223 & 1.8741 & 101.47 & 5.2144 & 1.8398 \\
\hline $1957 / 58$ & 100.66 & 5.1705 & 1.8220 & 104.11 & 5.1762 & 1.9705 & 99.93 & 3.0317 & 1.8955 & 102.70 & 5.1823 & 1.9072 \\
\hline $1958 / 59$ & 101.14 & 5.2060 & 1.9126 & 103.00 & 5.1936 & 2.0309 & 100.45 & 3.1409 & I. 9851 & 104.24 & 5.2237 & 2.0501 \\
\hline $1959 / 60$ & 102.91 & 5.2531 & 2.0808 & .104 .57 & 5.2415 & 2.2119 & 102.21 & 3.1878 & 2.1586 & 107.18 & 5.2766 & 2.2832 \\
\hline $1960 / 61$ & 102.61 & 5.0999 & 2.0727 & 103.14 & 5.0943 & 2.1274 & 101.94 & 3.1359 & 2.1479 & 108.03 & 5.1282 & 2.3265 \\
\hline $1961 / 62$ & 102.19 & 5.1244 & 2.0787 & .102 .37 & 5.1162 & 2. 1232 & 101.53 & 3.1674 & 2.1532 & 108.78 & 5.1583 & 2.3855 \\
\hline $1962 / 63$ & 103.46 & 5.2825 & 2.0256 & 103.25 & 5.2824 & 2.0276 & 102.79 & 3.2734 & 2.0977 & 111.37 & 5.3231 & 2.3771 \\
\hline $1963 / 64$ & 106.99 & 5.5316 & 2.1864 & 105.82 & 5.5250 & 2.1603 & 106.32 & 3.4731 & 2.2619 & 116.49 & 5.5800 & 2.6234 \\
\hline $1964 / 65$ & 110.34 & 5.5709 & 2.3513 & 108.51 & 5.5662 & 2.3011 & 109.67 & 3.5294 & 2.4307 & 121.53 & 5.6256 & 2.8827 \\
\hline $1965 / 66$ & 110.39 & 6.0795 & 2.0859 & 110.98 & 6.0793 & 2.1288 & 109.66 & 3.7431 & 2.1615 & 121.80 & 5.6185 & 2.6250 \\
\hline $1966 / 67$ & 113.13 & 6.8205 & 2.0711 & 113.20 & 6.7726 & 2.2150 & 112.42 & 4.2618 & 2.1430 & 125.04 & 5.8231 & 2.6802 \\
\hline $1967 / 68$ & 116.93 & 7.5703 & 2.3255 & 115.27 & 7.5049 & 2.4386 & 116.24 & 4.8161 & 2.4013 & 129.46 & 6.0181 & 3.0979 \\
\hline $1968 / 69$ & 120.53 & 8.2549 & 2.3008 & 117.03 & 8.1909 & 2.3016 & 119.85 & 5.3178 & 2.3720 & 133.67 & 6.1629 & 3.1531 \\
\hline $1969 / 70$ & 123.72 & 8.9508 & 2.5549 & 118.41 & 8.8734 & 2.4971 & 123.07 & 5.8414 & 2. 6292 & 137.45 & 6.3148 & 3.5993 \\
\hline $1970 / 71$ & 125.84 & 8.6849 & 2.5790 & 117.66 & 8.7291 & 2.4213 & 125.30 & 5.8753 & 2.6406 & 140.04 & 5.7988 & 3.7337 \\
\hline $1971 / 72$ & 125.67 & 8.8518 & 2.7290 & 116.36 & 8.9161 & 2.5313 & 125.17 & 6.0612 & .2 .7893 & 140.10 & 5.5915 & 4.0631 \\
\hline $1972 / 73$ & 129.51 & 9.7910 & 3.0846 & 118.36 & 9.7144 & 2.8224 & 128.99 & 6.6861 & 3.1540 & 144.64 & 5.8499 & 4.7222 \\
\hline $1973 / 74$ & 138.94 & 10.9766 & 3.1045 & 125.87 & 10.7814 & 2.9734 & 138.42 & 7.5710 & 3.1701 & 155.45 & 6.2011 & 4.8807 \\
\hline $1974 / .75$ & 140.42 & 12.2775 & 2.9748 & 124.53 & 11.9875 & 2.9145 & 139.99 & 8.6691 & 3.0281 & 157.39 & 6.5722 & 4.7969 \\
\hline $1975 / 76$ & 137.46 & 13.0573 & 2.8715 & 126.24 & 12.7908 & 2.9108 & 136.92 & 8.9709 & 2.9348 & 154.36 & 6.6518 & 4.7513 \\
\hline $1976 / 77$ & 136.14 & 13.6533 & 3.1663 & 124.57 & 13.3616 & 3.2300 & 135.62 & 9.4165 & 3.2341 & 153.15 & 6.6327 & 5.3823 \\
\hline Mean & 116.16 & 7.6251 & 2.3716 & 112.75 & 7.6722 & 2.3955 & 116.01 & 5.0568 & 2.4601 & 127.35 & 5.7594 & 3.2458 \\
\hline
\end{tabular}


To simulate the effects of taxing wine at the same rate as beer, we impose a wine tax equal to the beer tax in 1956/57 and then adjust it in all subsequent years to keep it equal to the beer tax. To do this, we write $t_{2}^{s}$ for the simulated value of the tax rate for wine and define it as follows. In 1955/56 it takes the value zero (which is also the observed value of $t_{2}$ in that year; see Table 12) and in all subsequent years it is equal to the observed beer tax rate $t_{1}$. Applying the same argument that led to equation (25), simulated minus actual consumption can then be expressed as

$$
D q_{i t}^{s}-D q_{i t}=\left(\pi_{i 2} / \bar{w}_{i t}\right)\left[D\left(1+t_{2 t}^{S}\right)-D\left(1+t_{2 t}\right)\right]
$$

The results of this simulation are given in columns 4-6 of

Table 13 and columns 7-9 of Table 14. On average, the tax causes the annual growth in wine consumption to be about 1.8 percentage points lower than actual. Simulated consumption of wine in $1976 / 77$ is 9.4 litres per capita, which is $(9.4165-13.6533) / 13.6533=31.0$ percent lower than actual. The effect of the wine tax is to lower beer consumption by a small amount to 135.6 litres in $1976 / 77$ and to increase spirits consumption to 3.23 litres. Hence, the fact that wine escaped a substantial tax does account for a large part of the observed growth in consumption over this period.

In the final simulation we take out the trend-like changes in tastes by setting to zero the constant terms in the demand equations of Table 7. Simulated minus actual consumption can be expressed for this case as

$$
\mathrm{Dq}_{i t}^{\mathrm{s}}-\mathrm{Dq}_{i t}=-\left[\left(\delta_{i} / \bar{w}_{i t}\right) \mathrm{D}_{t}+\left(\psi_{i} / \overrightarrow{\mathrm{w}}_{i t}\right)\left(1-\mathrm{D}_{t}\right)\right]
$$

and the results are given in the last three columns of Tables 13 and 14 . From Table 13, taking out this trend has the effect on average of beer consumption growing by .6 percentage points per annum more than actual, wine growing by 3.4 percentage points less and spirits 2.5 points more. To summarize, the simulations indicate that there are two reasons for the rapid growth of wine consumption. First, wine has not attracted a substantial tax, whereas beer has done so. Second, there has been a 
significant trend-like shift in preferences toward wine, away from beer and spirits. We also found that the observed changes in all alcohol taxes contributed very little to the growth of wine.

\section{THE WELFARE COST OF ALCOHOL TAXES}

In this section we measure the welfare cost of alcohol taxes by the reduction in consumer surplus not offset by government revenue from the taxes. This welfare cost can be expressed as (Harberger, 1964)

$$
W=-\frac{1}{2} \sum_{i=1}^{3} \sum_{j=1}^{3} T_{i} S_{i j} T_{j},
$$

where $T_{i}=t_{i} P_{i}^{0}$ is the tax per unit of $i$ measured in terms of dollars and $s_{i j}=\partial q_{i} / \partial p_{j}$ with real income constant. Dividing (26) by income $M$, the cost can be formulated as a fraction of $M$ as (see Appendix)

$$
\frac{W}{M}=-\frac{1}{2} \sum_{i=1}^{3} \sum_{j=1}^{3} \frac{t_{i}}{1+t_{i}} \pi_{i j} \frac{t_{j}}{1+t_{j}} \text {, }
$$

where $\pi_{i j}$ is the $(i, j)^{\text {th }}$ unconditional slutsky coefficient and $t_{i}=T_{i} / p_{i}^{0}$ is the tax rate on $i$. Using (20), (27) can be decomposed into the cost

(i) within the alcoholic beverages group and (ii) between alcoholic beverages and all other goods,

(28)

$$
\left\{\begin{array}{cc}
\sum_{i=1}^{\frac{1}{2}} \sum_{j=1}^{3} \sum_{j=\frac{t_{i}}{1+t_{i}}}^{3} \pi_{i j} \frac{t_{j}}{1+t_{j}} & \text { (total cost) } \\
=-\frac{1}{2} \sum_{i=1}^{3} \sum_{j=1}^{3} \frac{t_{i}}{1+t_{i}} \pi_{i j}^{g} \frac{t_{j}}{1+t_{j}} & \begin{array}{l}
\text { (cost within alcoholic } \\
\text { beverages group) }
\end{array} \\
-\frac{1}{2} \phi \theta_{g}\left(1-\theta_{g}\right) \sum_{i=1}^{3} \sum_{j=1}^{3} \frac{t_{i}}{1+t_{i}} \theta_{i}^{\prime} \theta_{j}^{\prime} \frac{t_{j}}{1+t_{j}} & \begin{array}{l}
\text { (cost between alcoholic } \\
\text { beverages and all } \\
\text { other goods). }
\end{array}
\end{array}\right.
$$

We evaluate (28) with the tax data given in Table 12 and the estimates given in Tables 5 and 7. The results are given in Table 15. 
AUSTRALIA, $1955 / 56-1976 / 77$

Welfare cost as a fraction of total consumption expenditure $\times 100$

\section{Within alcoholic}

beverages group

\section{Between alcoholic beverages}

and all other goods
Total =

within + between
Total welfare cost

Dollars

per capita

$$
-\frac{1}{2} \sum_{i=1}^{3} \sum_{j=1}^{3} \frac{t_{i}}{1+t_{i}} \pi_{i j} \frac{t_{j}}{1+t_{j}}
$$

As a

percentage of alcohol

expenditure

$$
\frac{(3)}{100} \times M
$$

$100 \times(4) / M_{g}$

(5)

(4)
As a

percentage of revenue from alcohol taxes

$100 \times(4) / R$
(2)

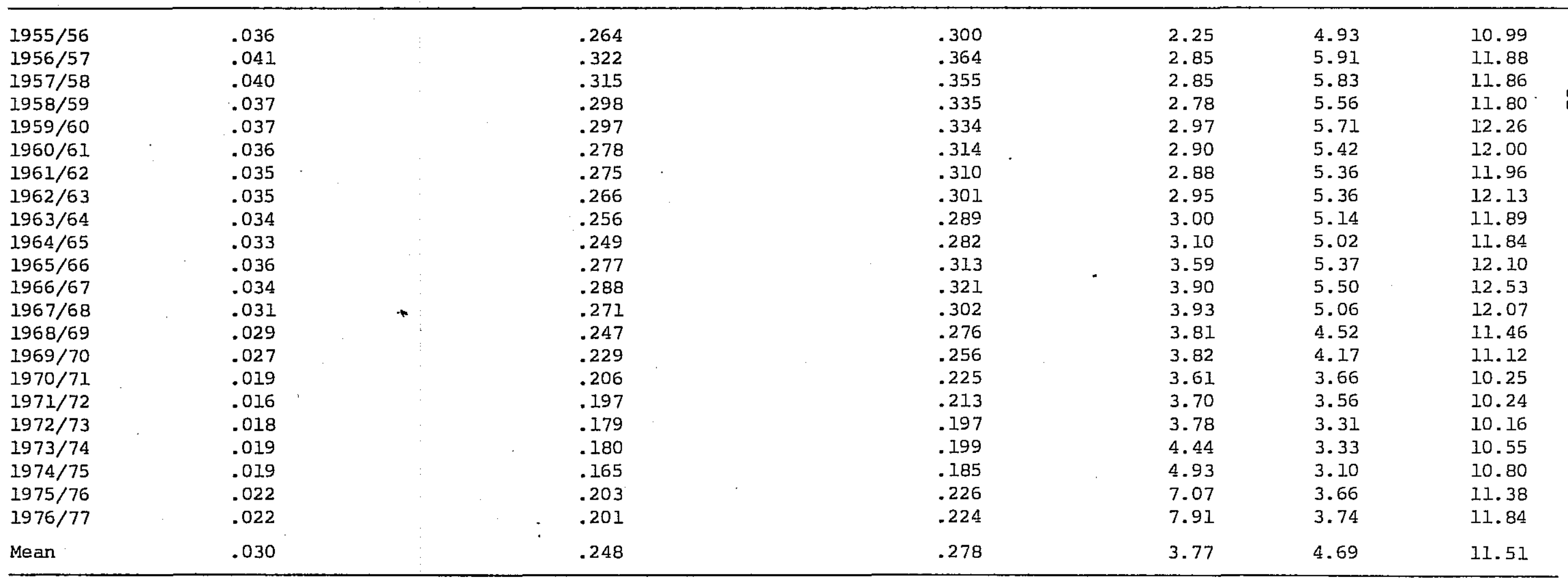

\begin{tabular}{l}
.300 \\
.364 \\
.355 \\
.335 \\
.334 \\
.314 \\
.310 \\
.301 \\
.289 \\
.282 \\
.313 \\
.321 \\
.302 \\
.276 \\
.256 \\
.225 \\
.213 \\
.197 \\
.199 \\
.185 \\
.226 \\
.224 \\
.278 \\
\hline
\end{tabular}

(6)

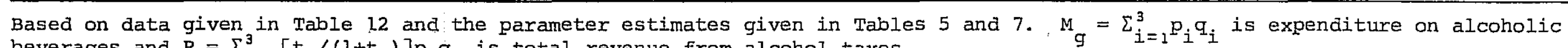
beverages and $R=\sum_{i=1}^{3}\left[t_{i} /\left(1+t_{i}\right)\right] p_{j} q_{i}$ is total revenue from alcohol taxes. 
In $1976 / 77$ the welfare cost is .2 percent of income (total consumption expenditure) or $\$ 7.91$ per capita (in current dollars). This represents 3.7 percent of expenditure on alcoholic beverages and 11.8 percent of government revenue from alcohol taxes. The within group component represents about 10 percent of the total cost.

In the previous section we simulated the effects of the imposition of a tax on wine at the same rate as that on beer. The simulated taxes are given in Table 16. We now apply the above analysis to measure the welfare cost of this tax package and the results are given in Table 17. As the imposition of the wine tax goes in the direction of having uniform tax rates, the within group cost falls in relation to what it was previously. However, the between group and all other goods cost rises sufficiently to increase the total cost to $\$ 8.72$ per capita in $1976 / 77$.

\section{CONCLUDING COMMENTS}

In this paper we have indicated how the system-wide approach to consumer demand can be extended so that it can be applied to quite narrowly defined commodity groups. Such applications have a number of attractions from the viewpoint of policy analysis for business and government.

- We analysed the consumption of beer, wine and spirits to illustrate the general principles and used the demand model for (i) a number of simulations designed to analyse the rapid growth of wine consumption and (ii) to measure the welfare cost of alcohol taxes. 
TABIE 16

SIMULATED ALCOHOL TAXES:

AUSTRALIA，1955/56 - 1976/77

Tax revenues

(Dollars per capita)

Year

wine spirits

$\frac{t_{1}^{s}}{1+t_{1}^{s}} p_{1}^{s} q_{1}^{s}$

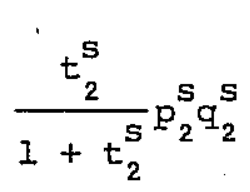

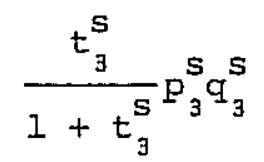

Total
Alcohol

\section{0}

$1955 / 56$

$1956 / 57$

$1957 / 58$

$1958 / 59$

$1959 / 60$

$1960 / 61$

$1961 / 62$

$1962 / 63$

$1963 / 64$

$1964 / 65$

$1965 / 66$

$1966 / 67$

$1967 / 68$

$1968 / 69$

$1969 / 70$

$1970 / 71$

$1971 / 72$

$1972 / 73$

$1973 / 74$

$1974 / 75$

$1975 / 76$

$1976 / 77$

Mean

\begin{tabular}{lr}
18.33 & \multicolumn{1}{l}{0} \\
21.56 & 3.36 \\
21.61 & 3.43 \\
21.02 & 3.48 \\
21.44 & 3.74 \\
21.37 & 3.81 \\
21.27 & 3.83 \\
21.58 & 3.99 \\
22.31 & 4.10 \\
23.03 & 4.29 \\
26.17 & 5.41 \\
27.26 & 6.10 \\
28.28 & 6.82 \\
29.10 & 7.98 \\
29.72 & 8.60 \\
29.95 & 7.92 \\
30.41 & 8.07 \\
31.52 & 8.49 \\
34.18 & 9.00 \\
34.70 & 9.79 \\
49.97 & 15.68 \\
53.03 & 17.19 \\
28.08 & \\
& 6.59
\end{tabular}

2. 14

2. 36

2. 36

2. 48

2. 73

2.74

2.77

2.68

. 2.88

3.10

3.43

3.80

4. 22

4.08

4.54

4. 48

4.73

5.35

7.86

10.92

12.09

13.69

4. 79
Tax rates $\times 100$

(Percentages of pre-tax prices)

Beer Wine Spirits

$t_{1}^{s} \quad t_{2}^{s} \quad t_{3}^{s}$

\begin{tabular}{llcl}
20.47 & 117.198 & 0 & 38.351 \\
27.28 & 141.132 & 141.132 & 48.401 \\
27.41 & 137.090 & 137.090 & 47.588 \\
26.98 & 126.086 & 126.086 & 47.704 \\
27.91 & 124.296 & 124.296 & 48.524 \\
27.91 & 119.236 & 119.236 & 43.421 \\
27.87 & 117.250 & 117.250 & 43.133 \\
28.25 & 116.272 & 116.272 & 39.602 \\
29.28 & 111.358 & 111.358 & 38.773 \\
30.42 & 108.372 & 108.372 & 37.927 \\
35.01 & 119.674 & 119.674 & 42.436 \\
37.15 & 112.929 & 112.929 & 53.891 \\
39.32 & 104.365 & 104.365 & 53.254 \\
41.15 & 97.793 & 97.793 & 46.589 \\
42.87 & 90.491 & 90.491 & 44.862 \\
42.36 & 79.073 & 79.073 & 41.995 \\
43.21 & 74.356 & 74.356 & 41.749 \\
45.36 & 68.654 & 68.654 & 41.213 \\
51.05 & 61.598 & 61.598 & 53.584 \\
55.42 & 50.353 & 50.353 & 64.601 \\
77.74 & 64.761 & 64.761 & 64.965 \\
83.91 & 62.615 & 62.615 & 67.507 \\
39.47 & & & \\
& 100.225 & 94.898 & 47.730 \\
\hline & & &
\end{tabular}

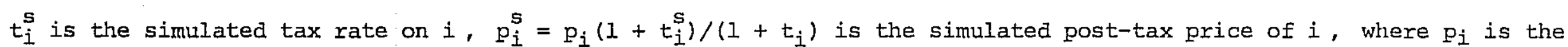
actual (post-tax) price and $t_{i}$ the actual tax rate, and $q_{i}^{s^{1}}$ is the simulated per capita consumption given in columns 7-9 of Table 14 . 。 
WELFARE COST OF SIMULATED ALCOHOL TAXES:

AUSTRALIA, 1955/56 - 1976/77

Welfare cost as a fraction of total consumption expenditure $\times 100$

Within alcoholic beverages group

Between alcoholic beverages and all other goods

Total =

within + between
Total welfare cost

\begin{tabular}{ccc}
\hline Dollars & As a & As a \\
per capita & $\begin{array}{c}\text { percentage } \\
\text { of alcohol } \\
\text { expenditure }\end{array}$ & $\begin{array}{c}\text { percentage } \\
\text { of revenue } \\
\text { from alcohol } \\
\text { taxes }\end{array}$ \\
$\frac{(3)}{100} \times \mathrm{M}$ & $100 \times(4) / \mathrm{M}_{\mathrm{g}}^{\mathrm{S}}$ & $100 \times(4) / \mathrm{R}^{\mathrm{S}}$
\end{tabular}

(4)

(5)

(6)

2.25

2.25

3. 32

3.33

3.23

3.45

3.38

3.36

3.46

3.52

3.63

4.19

4.49

4.51

4.40

4.40

4.13

4.23

4. 32

4.96

5.37

7.83

8. 72

4. 30

.319

$\begin{array}{lr}4.93 & 10.99 \\ 6.66 & 12.17 \\ 6.58 & 12.15 \\ 6.26 & 11.97 \\ 6.41 & 12.36 \\ 6.11 & 12.11 \\ 6.03 & 12.06 \\ 6.07 & 12.25 \\ 5.83 & 12.02 \\ 5.69 & 11.93 \\ 6.03 & 11.97 \\ 6.09 & 12.09 \\ 5.58 & 11.47 \\ 5.01 & 10.69 \\ 4.62 & 10.26 \\ 4.09 & 9.75 \\ 3.98 & 9.79 \\ 3.70 & 9.52 \\ 3.65 & 9.72 \\ 3.34 & 9.69 \\ 3.96 & 10.07 \\ 4.03 & 10.39 \\ 5.21 & 11.16\end{array}$

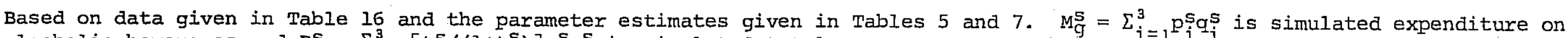
alcoholic beverages and $R^{S}=\sum_{i=1}^{3}\left[t_{i}^{S} /\left(I+t_{i}^{S}\right)\right] p_{i}^{S} q_{i}^{S}$ is simulated total revenue from alcohol taxes. 


\section{APPENDIX}

Unconditional Demand Equations

Letting $p=\left[p_{1}, \ldots, p_{n}\right]^{\prime}$ and $q=\left[q_{1}, \ldots, q_{n}\right]^{\prime}$, the consumer chooses $q$ to maximize the utility function $u(q)$ subject to the budget constraint $p^{\prime} q=M$. The first-order conditions are the budget constraint and $\partial u / \partial q=\lambda p$, where $\lambda$ is the marginal utility of income. Differentiating these conditions with respect to $p$ and M gives Barten's (1964) fundamental matrix equation,

$$
\left[\begin{array}{ll}
u & p \\
p^{\prime} & 0
\end{array}\right]\left[\begin{array}{cc}
\partial q / \partial M & \partial q / \partial p^{\prime} \\
-\partial \lambda / \partial M & -\partial \lambda / \partial p^{\prime}
\end{array}\right]=\left[\begin{array}{cc}
0 & \lambda I \\
I & -q^{\prime}
\end{array}\right]
$$

where $\mathrm{v}=\partial^{2} \mathrm{w} / \partial \mathrm{q} \partial \mathrm{q}^{\prime}$ and $\partial \mathrm{q} / \partial \mathrm{M}$ and $\partial \mathrm{q} / \partial \mathrm{p}^{\prime}$ are the income and price derivatives of the demand functions. Solving (AI) gives

(A2) $\quad \frac{\partial q}{\partial p^{\prime}}=\lambda U^{-1}-\frac{\lambda}{\partial \lambda / \partial M} \frac{\partial q}{\partial M} \frac{\partial q^{\prime}}{\partial M}-\frac{\partial q}{\partial M} q^{\prime}$

for the price derivatives and

$$
\frac{\partial q}{\partial M}=\frac{\partial \lambda}{\partial M} U^{-1} p
$$

for the income derivatives.

$$
\text { Defining } \mathrm{P}=\operatorname{diag}[\mathrm{p}] \text {, we premultiply (A2) by } \mathrm{P} \text { and postmultiply }
$$

by $P / M$ to give

$$
\mathrm{P} \frac{\partial \mathrm{q}}{\partial \mathrm{p}^{\prime}} \mathrm{P} / \mathrm{M}=\nu-\phi \theta \theta^{\prime}-\theta \mathrm{w}^{\prime},
$$

where $v=\lambda \mathrm{PU}^{-1} \mathrm{P} / \mathrm{M}=\left[\nu_{i j}\right], \phi=\frac{\lambda / M}{\partial \lambda / \partial \mathrm{M}}=\left(\frac{\partial \log \lambda}{\partial \log M}\right)^{-1}, \theta=\mathrm{P} \partial \mathrm{q} / \partial \mathrm{M}=\left[\theta_{i}\right]$ and $w=P q / M=\left[w_{i}\right]$. Dividing (A3) by $\partial \lambda / \partial M$ and premultiplying by $\lambda P / M$ gives

$$
\frac{\lambda / \mathrm{M}}{\partial \lambda / \partial \mathrm{M}} \mathrm{P} \frac{\partial \mathrm{q}}{\partial \mathrm{M}}=\lambda \mathrm{PU}^{-1} \mathrm{p} / \mathrm{M}=\left(\lambda \mathrm{PU}^{-1} \mathrm{P} / \mathrm{M}\right) \mathrm{l}
$$

where $l=[1, \ldots, 1]^{\prime}$, or 
(A5)

$$
\phi \theta=v i,
$$

which is equation (3) in vector form.

We write the demand equations in differential form as

$$
d q=\frac{\partial q}{\partial M} d M+\frac{\partial q}{\partial p^{\prime}} d p
$$

Premultiplying by $\mathrm{P} / \mathrm{M}$ gives

$$
W d(\log q)=\theta d(\log M)+\left(P \frac{\partial q}{\partial p^{\prime}} P / M\right) d(\log p),
$$

where $w=\operatorname{diag}[w]$. Substituting the right side of (A4) for $P \frac{\partial q}{\partial p^{\prime}} P / M$, we obtain

$$
\begin{aligned}
w d(\log q)= & \theta d(\log M)+\left(\nu-\phi \theta \theta^{\prime}-\theta w^{\prime}\right) d(\log p) \\
& =\theta[d(\log M)-d(\log P)]+v\left(I-1 \theta^{\prime}\right) d(\log p),
\end{aligned}
$$

where $d(\log P)=w^{\prime} d(\log P)$ and where we have used (A5) for substitute $v i$ for $\phi \theta$. The term $d(\log M)-d(\log P)$ is the change in real income, which we write as d(log $Q)$. Taking the differential of the budget constraint, we obtain $w^{\prime} d(\log p)+w^{\prime} d(\log q)=d(\log M)$, se that $d(\log Q)=w^{\prime} d(\log q)$ $[$ see below equation $(1)]$. Writing $d\left(\log P^{\prime}\right)=\theta^{\prime} d(\log p)$ for the Frisch price index, (A6) can be expressed as

$$
w d(\log q)=\theta d(\log q)+v\left[d(\log p)-l d\left(\log P^{\prime}\right)\right]
$$

which is equation (1) in vector form.

Derivation of Equations (7) and (8)

Equation (7) is obtained by summing both sides of (6) over $i \in S_{g}$. The derivation of the variable on the left and the first term on the right of equation (7) is straightforward. We obtain the substitution term as follows. The sum over $i \in S_{g}$ of the substitution term of equation (6) is

$$
\sum_{i \in S_{g}} \sum_{j \in S_{g}} v_{i j} d\left(\log \frac{p_{j}}{p^{\prime}}\right)=\phi \sum_{j \in S_{g}} \theta_{j}\left[d\left(\log p_{j}\right)-d\left(\log P^{\prime}\right)\right],
$$


where we have used $\Sigma_{i \in S_{g}} \nu_{i j}=\phi \theta_{j}$, which follows from the symmetry of $\left[\nu_{i j}\right]$ and (5). Since $\theta_{g}=\Sigma_{j \in S_{g}} \theta_{j}$, the second member of (A7) can be expressed as

$$
\phi \theta_{g}\left[\sum_{j \in S_{g}} \frac{\theta_{j}}{\theta_{g}} d\left(\log p_{j}\right)-d\left(\log P^{\prime}\right)\right]=\phi \theta_{g}\left[d\left(\log P_{g}^{\prime}\right)-d\left(\log P^{\prime}\right)\right],
$$

where $d\left(\log P_{g}^{\prime}\right)=\Sigma_{j \in S_{g}}\left(\theta_{j} / \theta_{g}\right) d\left(\log p_{j}\right)$ is the Frisch price index of the group. The second member of (A8) is the substitution term of equation (7).

$$
\text { To derive equation (8), we rearrange (6) and (7) to give }
$$

$$
\begin{aligned}
& \mathrm{d}(\log Q)=\frac{w_{i}}{\theta_{i}} \mathrm{~d}\left(\log q_{i}\right)-\sum_{j \in S_{g}} \frac{v_{i j}}{\theta_{i}} \mathrm{~d}\left(\log \frac{p_{j}}{\mathrm{P}^{\prime}}\right) \\
& \mathrm{d}(\log Q)=\frac{\mathrm{w}_{g}}{\theta_{g}} \mathrm{~d}\left(\log \mathrm{Q}_{g}\right)-\phi d\left(\log \frac{\mathrm{P}^{\prime}}{\mathrm{P}^{\prime}}\right) .
\end{aligned}
$$

Equating the right side of (A9) with that of (A10) and rearranging gives

$$
\begin{aligned}
w_{i} d\left(\log q_{i}\right)= & \frac{\theta_{i}}{\theta_{g}} w_{g} d\left(\log q_{g}\right)+\sum_{j \in S_{g}} v_{i j} d\left(\log p_{j}\right) \\
& -\sum_{j \in S_{g}} v_{i j} d\left(\log P^{\prime}\right)-\phi \theta_{i} d\left(\log P_{g}^{\prime}\right)+\phi \theta_{i} d\left(\log P^{\prime}\right) \\
= & \frac{\theta_{i}}{\theta_{g}} w_{g} d\left(\log q_{g}\right)+\sum_{j \in S} v_{i j}\left[d\left(\log p_{j}\right)-d\left(\log P_{g}^{\prime}\right)\right],
\end{aligned}
$$

which follows from (5). This is equation (8).

The Construction of $\mathrm{P}_{0}$

We write the log-change in the consumer price index (DP*) as a weighted average of the price log-changes of the $n$ goods, with the averages of the budget shares as weights. With the alcoholic beverages the first three goods, we have

$$
\mathrm{DP}_{t}^{*}=\sum_{i=1}^{3} \overline{\mathrm{w}}_{i t} \mathrm{Dp}_{i t}+\sum_{i=4}^{\mathrm{n}} \overline{\mathrm{w}}_{i t} \mathrm{Dp}_{i t}=\overline{\mathrm{w}}_{\mathrm{gt}} \mathrm{DP}_{\mathrm{gt}}+\left(1-\overline{\mathrm{w}}_{\mathrm{gt}}\right) \mathrm{DP} \mathrm{Dt}^{\prime}
$$


Barten, A.P. (1964). "Consumer Demand Functions Under Conditions of Additive Preferences." Econometrica 32: 1-38.

(1977). "The Systems of Consumer Demand Functions Approach: A Review." Econometrica 45: 23-51.

Brown, A. and A. Deaton (1972). "Surveys in Applied Economics: Models of Consumer Behavior." Economic Journal 82: 1145-1236.

Clements, K.W. (1981). "Changes in the size of the Traded Goods Sector: Theory and Applications." Empirical Economies, forthcoming. and P. Nguyen (1980). "Money Demand, Consumer Demand and Relative Prices in Australia." Economic Record 56: 338-46. and H. Theil (1979). "A Cross-Country Analysis of Consumption Patterns." Report 7924 of the Center for Mathematical Studies in Business and Economics, The University of Chicago.

Harberger, A.C. (1964). "Taxation, Resource Allocation and Welfare." In The Role of Direct and Indirect Taxes in the Federal Reserve System. Princeton: Princeton University Press for the NBER and the Brookings Institute. Reprinted in A.C. Harberger (1974), Taxation and Welfare. Chicago: The University of Chicago Press.

Phlips, I. (1974). Applied Consumption Analysis. Ansterdam: North-Holland Publishing Company.

Powell, A.A. (1974). Empirical Analytics of Demand Systems. Lexington, MA: D.C. Heath. 
where $\bar{w}_{g t}=\Sigma_{i=1}^{3} \bar{w}_{i t}, D_{g t}=\Sigma_{i=1}^{3}\left(\bar{w}_{i t} / \bar{w}_{g t}\right) D_{i t}$ is the Divisia price index of the group and $D_{0 t}=\Sigma_{i=4}^{n}\left[\bar{w}_{i t} /\left(1-\bar{w}_{g t}\right)\right] D p_{i t}$ is the Divisia price index of all other goods. We express DP ot in terms of observables by rearranging (A11) to give

$$
D_{0 t}=\left(D P_{t}^{*}-\bar{W}_{g t} D P g t\right) /\left(1-\bar{W}_{g t}\right)
$$

which is the equation used to define $\mathrm{DP}_{\text {ot }}$.

\section{Derivation of Equation (27)}

We divide both sides of (26) by $M$ and then multiply and divide the right by $p_{i} p_{j}$ to give

$$
\begin{aligned}
\frac{W}{M} & =-\frac{1}{2} \sum_{i=1}^{3} \sum_{j=1}^{3} \frac{T_{i}}{P_{i}} \frac{P_{i} P_{j}}{M} s_{i j} \frac{T_{j}}{P_{j}} \\
& =-\frac{1}{2} \sum_{i=1}^{3} \sum_{j=1}^{3} \frac{t_{i}}{1+t_{i}} \frac{P_{i} P_{j}}{M} s_{i j} \frac{t_{j}}{1+t_{j}},
\end{aligned}
$$

as $T_{i}=t_{i} p_{i}^{0}$ and $P_{i}=\left(1+t_{i}\right) p_{i}^{0}$. To establish that this is equivalent to (27) we need to show that $\pi_{i j}=\left(p_{i} p_{j} / M\right) s_{i j}$. To do this, consider the change in demand for $i$ when (i) real income is constant and (ii) oniy $p_{j}$ changes. From (A6) this is

$$
w_{i} d\left(\log q_{i}\right)=\left(v_{i j}-\phi \theta_{i} \theta_{j}\right) d\left(\log p_{j}\right)=\pi_{i j} d\left(\log p_{j}\right),
$$

where the second step is based on (10) and (20). This can be written as

$$
\frac{p_{i}}{M} d_{i}=\pi_{i j} \frac{d p_{j}}{p_{j}}
$$

so that

$$
d q_{i}=\left(M / p_{i} p_{j}\right) \pi_{i j} d p_{j}
$$

As real income is constant, $\left(M / p_{i} p_{j}\right) \pi_{i j}=s_{i j}$, so that $\pi_{i j}=\left(p_{i} p_{j} / M\right) s_{i j}$. 
FOOTNOTES

1. We use Wymer's (1977) estimation program RESIMUL.

2. That is, these coefficients have $|t|-v a l u e s$ greater than two.

3. As one of three estimating equations is redundant, the homogeneity constraint (12) involves two restrictions while symmetry (13) involves one.

4. See, e.g., Clements (1981), Clements and Nguyen (1980), Clements and Theil (1979), Theil (1975/76, 1980) and Theil and Suhm (1981).

5. For a further analysis, see Theil (1975/76, pp. 31-2).

6. These are customs and excise taxes. Full details and sources of these data are given in a separate Appendix, available on request. 